\title{
EVALUATION OF A MAILED PLANNING SURVEY
}

\section{JUNE 1972 - NUMBER 12}

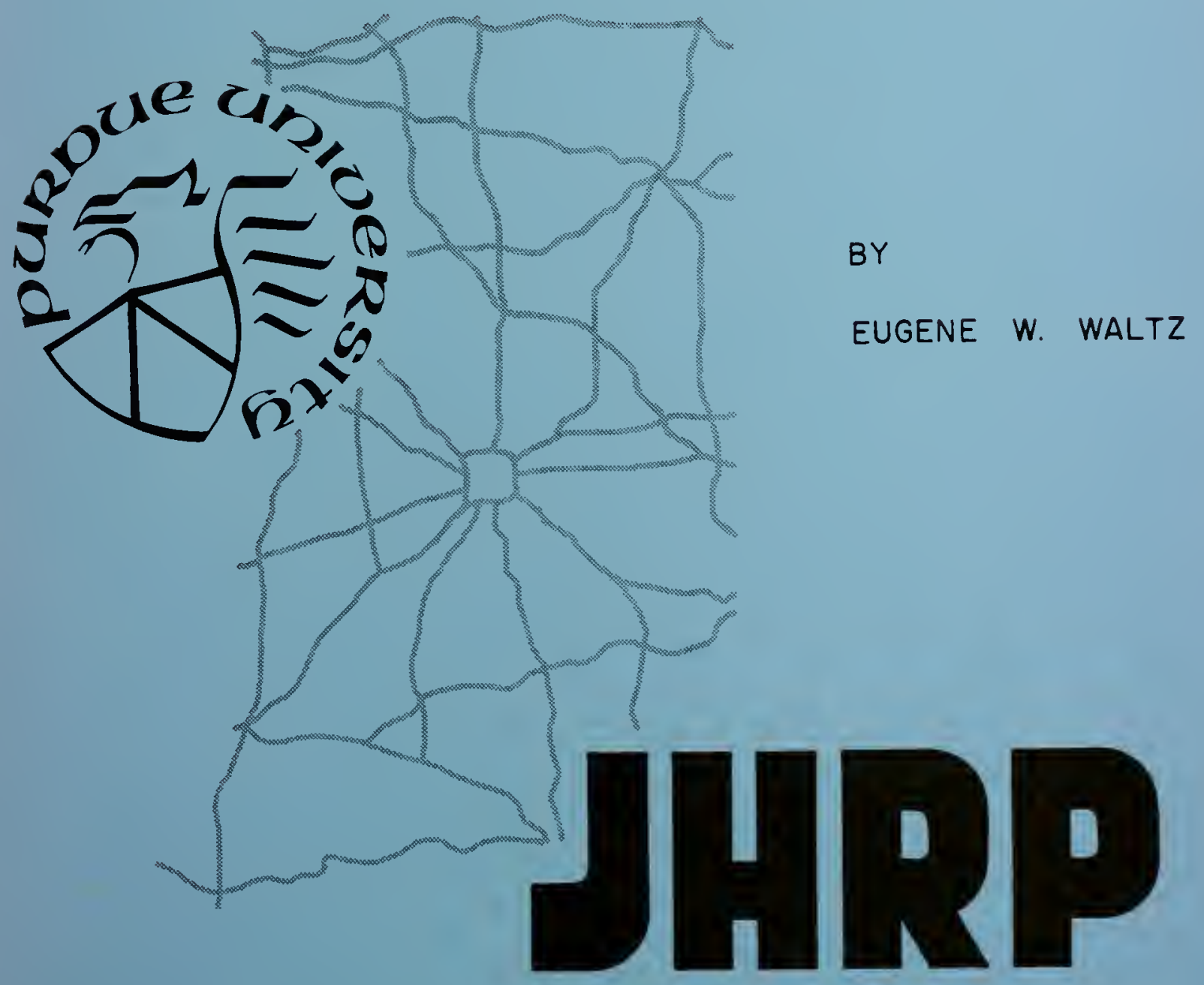

JOINT HIGHWAY RESEARCH PROJECT PURDUE UNIVERSITY AND

INDIANA STATE HIGHWAY COMMISSION 

T0: J.F. Mclaughlin, Director Joint Highway Research Project

FROM: H. L. Michael, Associate Director Joint Highway Research Project
June 22, 1972

Project: C-36-69K

File: $\quad 3-7-11$

The attached Final Report is presented as information to the Advisory Board as it has been financed by General Electric Corporation funds and not by funds of the JHRP. It is titled "Evaluation of a Mailed Planning Survey", authored by Eugene W. Waltz, Graduate Assistant in Research on our staff; and directed by Professor W. L. Grecco.

The report is of a methodological evaluation of a mailed planning survey. Emphasis was placed on the value and effect of several follow-up procedures to obtain a greater response. As a study for evaluation, a survey of community needs in Greater Lafayette, Indiana was included. The findings of this portion of the study are of value to the Tippecanoe County Area Plan Commission and to the Greater Lafayette Area Transportation and Development Study.

The Report is presented to the Board as information. Respectfully submitted,

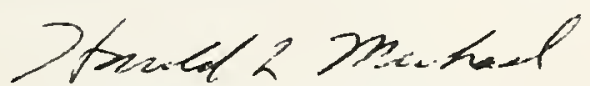

Harold L. Michael Associate Director

HLM : ms

cc: W. L. Dolch

R. L. Eskew

W. H. Goetz

W. L. Grecco

M. J. Gutzwiller

G. K. Hallock
M. E. Harr

R. H. Harre11

M. L. Hayes

R. D. Miles

J. W. Miller

C. F. Scholer
M. B. Scott

J. A. Spooner

N. W. Steinkamp

H. R. J. Walsh

K. B. Woods

E. J. Yoder 
Final Report

EVALUATION OF A MAILED PLANNING SURVEY

\author{
by \\ Eugene W. Waltz \\ Graduate Assistant in Research
}

Joint Highway Research Project

Project No.: C-36-69K

File No.: 3-7-11

Partially Financed by Funds Made Available by General Electric Corporation

Purdue University

Lafayette, Indiana

June 22,1972 


\section{ACKNOWLEDGMENTS}

The author is most appreciative of the support and guidance given by his major professor, Dr. William L. Grecco.

For his helpful direction at different stages of the research, the author is grateful to Professor Harold L. Michael.

Sincere thanks are due Dr. Harvey H. Marshall of the Sociology Department for his conducive support and cooperation in advising the author on this study and in other areas of the author's graduate work.

Further gratitude is noted for the contributions and suggestions of $\mathrm{Mr}$. T. William Patterson during various parts of the design and pre-test of the survey questionnaire. Also, for their assistance during the initial stages of the survey design, the author is grateful to Dr. Harry A. Potter and Miss Deborah Meyer of the Sociology Department.

The cooperation of Mr. Joseph A. Fletcher and Tippecanoe County Area Planning with the conduct of this study is also appreciated.

The author would like to thank the Indiana State Highway Commission and the General Electric Corporation for their financial support during the course of this study. 
Digitized by the Internet Archive in 2011 with funding from

LYRASIS members and Sloan Foundation; Indiana Department of Transportation 
TABLE OF CONTENTS

$\underline{\text { Page }}$

LIST OF TABLES...................... v

LIST OF FIGURES ..................... vii

ABSTRACT ......................... viii

CHAPTER I I INTRODUCTION.................. 1

Survey Applications.................. $\frac{1}{5}$

Purpose and Scope................... 5

CHAPTER II. BACKGROUND.................. 6

Advantages and Disadvantages of Mail Surveys.. 6

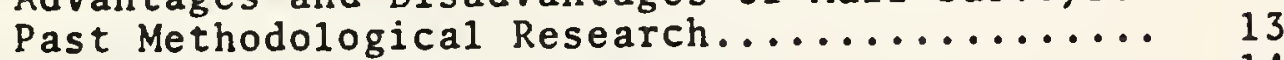

Factors Affecting Response........... 14

Follow-Up Procedures................ 16

CHAPTER III. STUDY DESIGN................. 21

Study Population.................... 21

Selected Follow-Up Procedures............. 22

Selected Procedure and Characteristics....... 24

Procedural Design................. 24

Individual and Household Characteristics. 25

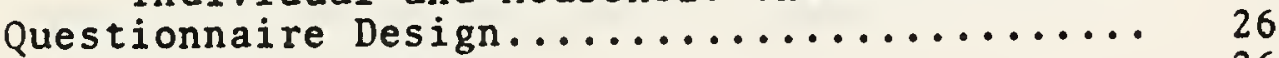

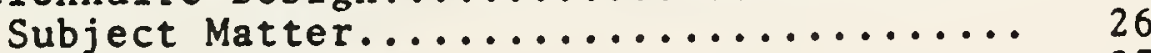

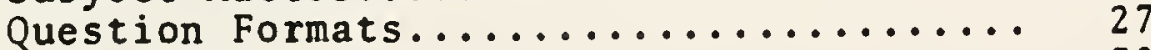

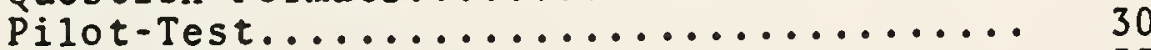

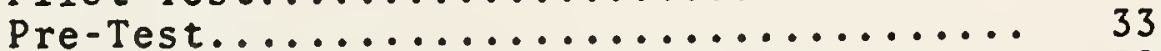

Final Design...................... 38

other Considerations.................. 39

CHAPTER IV. SAMPLING PROCEDURES............ 41

Initial Sample................... 41

Non-Mail Follow-Up Groups.............. 43 
TABLE OF CONTENTS (Continued)

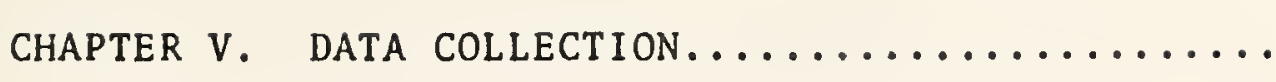

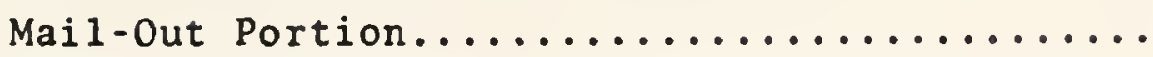

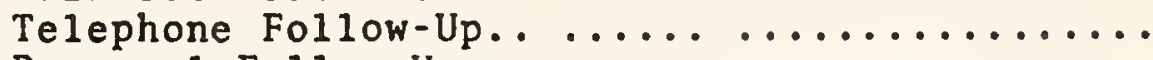

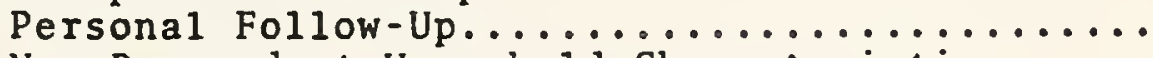

Non-Respondent Household Characteristics......

CHAPTER VI. RESULTS..................... 53

Methodological Data.................. 53

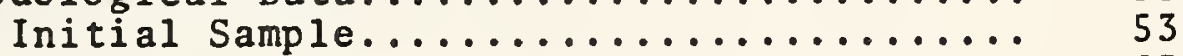

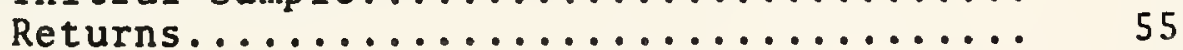

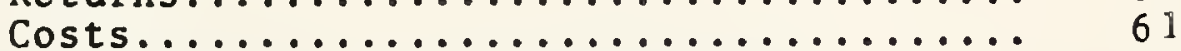

Respondents and Non-Respondents....... 64

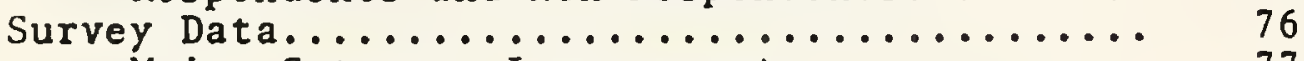

Major Category Improvement.......... 77

Specific Improvements Suggested........ 86

Importance of Specific Projects......... 90

CHAPTER VII. CONCLUSIONS................... 94

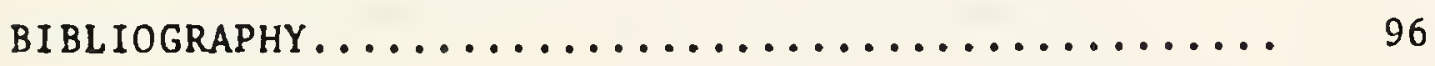

APPENDICES

Appendix A - Pilot-Test Questionnaire....... 99

Appendix B - Pre-Test Questionnaire......... 101

Appendix C - Final Questionnaire Design...... 107

Appendix D - Additional Survey Data......... 114 
LIST OF TABLES

$\underline{\text { Table }}$

Page

1 Return Rate for Different Collection

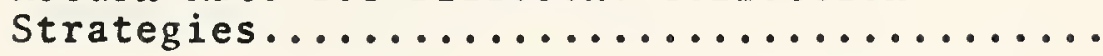

2 Returns for a Travel Survey By Mail and

Interview.......................

3 Pre-Test Response to the General and

Specific Questions By Major Category........

4 Dwelling Unit Characteristics of Initial

Sample........................ 54

5 Survey Response by Procedural Stage....... 54

6 Return Rates of Other Mailed Community

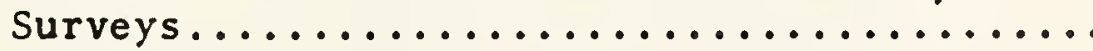

7 Dwelling Unit Characteristics of Telephone and Personal Follow-Up Groups.............

8 Data Collection Costs by Stage........... 62

9 Cumulative Survey Response by Selected Characteristics..................... 65

10 Respondents and Non-Respondents by Enumerated Characteristics............. 68

11 Survey Response by Resident Time......... 69

12 Survey Response by Resident Time Controlling on SES, Tenure, Dwelling Unit Type, and

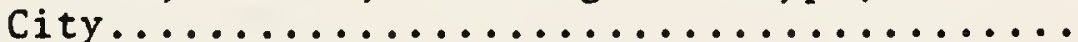

13 Survey Respondents and Study Population by Age and Sex........................ 72

14 Wave of Return by Selected Characteristics.. 74

15 Categories Needing the Most Improvement by Wave of Return..................... 


\section{LIST OF TABLES (Continued)}

Table

Page

16 Categories Needing the Most Improvement

by Characteristic Sub-Groups.............

17 Most Frequently Suggested Specific

Improvements.....................

18 Mean Importance Scores of Specific

Community Projects................... 92

Appendix

Table

D1. Specific Suggestions for Improvements by Major Category................. 118 


\section{LIST OF FIGURES}

Figure

$\underline{\text { Page }}$

1 General and Specific Suggestions for Improvement by Major Category........... 79

2 Cumulative Mean Importance Scores of Specific Projects After Each Wave of

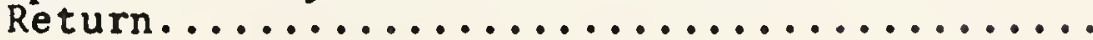

Appendix

Figure

C1 Final Questionnaire Design - Page 1....... 107

C2 Final Questionnaire Design - Page 2....... 108

C3 Final Questionnaire Design - Page 3-...... 109

C4 Final Questionnaire Design - Page 4....... 110

C5 Cover Letter.................... 111

C6 Post Card Reminder................. 112

C7 Cover Letter for Personal Follow-Up........ 113 
ABSTRACT

Waltz, Eugene William. M.S.E., Purdue Iniversity, Jume 1972. Evaluation of a Mailed Planning Survey. Major Professor: William L. Grecco.

A methodological evaluation of a mailed planning survey was made to obtain information which would help assess the application of mail surveys for providing planning information. The scope of the research was 1 imited to evaluating the combined application of mail and non-mail follow-up procedures for reducing non-response and total survey costs and to assessing how critical non-response might be to planning surveys.

A mailed planning survey of a small community nopulation $(<100,000)$ was conducted using mail, telephone, and personal follow-ups. Survey respondents were determined by selected sociodemographic characteristics, and the cost and contribution of the follow-up procedures were also determined. The survey obtained resident's opinions and suggestions for improvements in community facilities, services, and conditions over twelve major categories of community concern.

Survey response was found to be more strongly associated with the resident time of the respondents than it was with their age, sex, socioeconomic status, family status or size, tenure, or type of dwelling unit. Respondents were found more likely than 
non-respondents to be older, longer time residents, and owning a single unit dwelling. Non-mail follow-ups were found to be effective in reducing the typical socioeconomic bias found in the response to the mail-out portions.

On the basis of cost versus information obtained, the results indicated that the combined use of the mail approach with mail, telephone, and personal follow-ups could be comparable to the use of other methods for planning surveys having an informative purpose.

A trend analysis of the opinion data indicated that, for informative uses, the bias due to non-response may not result in any serious loss of information if over 60 percent return is achieved. A general consensus of opinion was found between various socio-demographic sub-groups on which major categories of comonity concern they thought were in the most need of improvement. The relative degree of dissatisfaction within major categories of community concern was found to vary more between different age-1inked, socioeconomic, and family status suh-groups, than it did hetween groups who differed on sex, tenure, or type of dwellig unit. 


\section{CHAPTER I}

INTRODUCTION

\section{Survey Applications}

Surveys of the economic base, land-use, transportation, and population predominate among those considered essential for urban planning. Recently, planners have come to be increasingly interested in using attitude and opinion survey data in the planning process. Although the experience in conducting social surveys for planning purposes is still limited, initial experiences in surveying urban resident's reactions indicate a wide range of application. For example, planning surveys have been conducted to obtain resident's general evaluation of their community environments [1], preferences for accessibility to selected neighborhood services [2], suggestions for needed community facilities and programs [3], attitudes about the relative importance of the livability features of their community [4], comments about subjects related to community objectives [5], etc. With this increased use of social surveys in the planning context has come:questions about what role survey data will have in the planning process. Answering these questions is beyond the scope of this method study. However, some indication should be given towards what use of survey data in planning this study was directed. 
The orientation of this study might best be indicated with the aid of a conceptual framework suggested by the sociologist-planner, Herbert Gans [6]. Gans defines two conceptual environments, the potential environment, that seen by the planner, and the effective environment, that version of the potential environment that is manifestly or latently adopted by users. The viewpoint of this study is that survey data of people's perceptions and reactions to community facilities, services, or conditions is, in part, descriptive information about the effective environment. This descriptive kind of information is not considered sufficient within itself for explaining why specific groups have particular preferences or for predicting what the effective environment will be. These latter purposes are more of an analytical or explanatory nature which presume a solid base of descriptive information which is currently not available [7]. This study is limited to the informative survey purpose on the premise that descriptive survey data can perform the role of giving the planner more information and insight about the effective environment.

In the past, planning agencies have relied upon public hearings and discussions with organized reference groups to obtain informative inputs from the public. Sample surveys offer an additional approach to obtain information from a wider cross-section of the general public. There are various survey approaches which could be taken. The mail and interview survey methods are predominately used. In part, the typical 
problems associated with mail and interview surveys still prevent most small community (less than 100,000 pop.) planning agencies from undertaking surveys more frequently. Both methods have their advantages and disadvantages depending on the specific survey situation and purpose.

The mail approach has a number of well-known drawbacks. The principal objection to mail surveys is that they typically involve a large non-response rate, and an unknown bias is involved in any assumption that those responding are representative of the combined total of respondents and non-respondents. Also, the self-administered mail questionnaire is not flexible for collecting attitude or opinion data which requires in-depth probing, sequential answering, or sophisticated scaling techinques. Even in those situations where the data sought could be obtained by mail, the political context within which various planning agencies operate still requires some effort to be made to obtain as unbiased a sample of the study population as possible. The response problem of mail surveys often precludes their consideration as a possible alternative and this may have contributed to their limited application in planning studies.

On the other hand, the interview technique can generally obtain a less biased sample and is more flexible in use than the mail approach. The costs involved with interview surveys, however, puts their periodic undertaking beyond the financial 
constraints of most planning agencies. The resulting practice has been to limit the use of interview surveys to only large scale or special purpose planning projects which provide sufficient funds. Then, the data are usually collected for only one point in time.

A large investment of time, money, and effort to collect opinion survey data is difficult for a planning agency to justify when it considers the time dependent relevance of such data. The periodic undertaking and a wider application of surveys would increase the informative input of survey data to planning since it is both a continuing and comprehensive process. In many situations, the type of data sought dictates the use of the interview method. In other instances though, either the mail or interview technique could be used when closer attention is given to the data sought and the actual use to which they will be put. For such situations, the economic advantage of using mail surveys with follow-up procedures makes their application in the planning context attractive for both periodic data collection and for situations where limited funds preclude the interview method. However, mail survey applications in planning have been limited. Associated with this limited experience is a lack of information which would help assess their combined use with follow-up methods in various planning situations to reduce overall survey costs and non-response. 


\section{Purpose and Scope}

The general objective of this research was to make a methodological evaluation of a mailed planning survey for the purpose of obtaining further information which would help assess the application of mail surveys in the planning context. The scope of the research was limited to assessing the suitability of the mail approach for planning surveys of the general population and its combined use with different follow-up procedures to reduce non-response and total survey costs. Using a mailed planning questionnaire with both mail and non-mail follow-up procedures, the primary study objectives were to determine the respondents and nonrespondents on selected individual and household characteristics and the cost and contribution of follow-up procedures for reducing non-response. An additional objective was to descriptively analyze the survey data and make some assessment of how critical the non-response might be to the informative survey purpose. 
CHAPTER II

BACKGROUND

The problems associated with collecting survey data have been the concern of social science and opinion survey researchers for some time. Considerable methodological research has been done in these fields to help assess the suitability of different data collection methods for various survey purposes. The results of past research does provide many of the guidelines for mail survey applications in the planning context. Before discussing this research, some of the advantages and disadvantages of using the mail technique [8], [9] will be reviewed with reference to its application by planning agencies.

\section{Advantages and Disadvantages of Mail Surveys}

As aforementioned, the problem of non-response is the major weakness of mail surveys. Those who answer a mail questionnaire may differ from the non-respondents thereby biasing the results. Also, non-response to mail surveys has been shown to be typically greater for lower socioeconomic status (SES) groups.

Mailed questionnaires are also limited on the type of data which they can collect. The validity of information obtained depends on the ability and willingness of the 
respondent to provide it. Possible misinterpretation of questions prevents many complex questions or scaling techniques from being used since no additional explanations can be given. Also, there is no control over the question answering sequence. If the internal validity of the data sought depends on answering sequence or in-depth probes, the mail questionnaire is probably not suitable. Furthermore, if spontaneous reactions are wanted, they couldn't be assured with self-administered questionnaires since they are usually perused before being answered. These factors and others limit mail surveys to collecting data which can be obtained by asking questions that are reasonably easy to answer to minimize misinterpretation. Because of the political dictates for equal representation in planning considerations, the non-response to mail surveys is the most serious limitation. The applicability of the mail approach would partially depend on the use of follow-up procedures to help overcome this non-response. Non-response has its own determinants which vary from survey to survey making it a non-random process. Almost invariably, the returns will not be representative of the original sample drawn. This problem cannot be completely solved. However, some assessment of how serious the non-response bias is to the intended use of the data can often be made. With the foregoing in mind, the mail technique still has many advantages which are 
important for considering its use in the planning context.

The major advantages of the mail approach is its economy. It permits a wide coverage for minimum expense and effort. For planning, this means larger sample sizes would be possible to increase the number of informative inputs. Also, it would allow wider geographical contact which to planning would be important since different conditions could exist in different areas of the community. To do this with the interview method would result in high manpower and transportation costs to cover a large and widely distributed sample. The small amount of manpower and organization required to conduct a mail survey would also be important for smaller planning agencies having limited operating staffs and budgets.

Although the mailed questionnaire does not permit the asking of complex questions, it does permit respondents more time to consider their answers and with a sense of privacy. Many questions which planning surveys might ask are likely to seek the affective component of a resident's belief, opinion, or attitude about different aspects of their physical community environment. These answers are not likely to be uppermost in the respondent's mind. In contrast to the interview situation, which might obtain more spontaneous reactions, the mail technique gives the respondent more time to think about his experiences in the community environment to help provide more thoughtfully considered answers. 
In view of the increasing interest of using survey data more often in planning for informative purposes, the main attraction of mail is its economic advantage in reducing overall survey costs which might allow more frequent survey undertaking. Yet, as stated before the response problems and the inflexibility of mailed questionnaires has often precluded a thorough consideration of their possible application with follow-up procedures. For example, Saroff and Levitan [7] discuss the use of opinion surveys in the planning process. They consider the direct interview to be a better approach than the mailed questionnaire because of the inflexibility of the latter and the characteristic low response from the lower SES groups. As a general consideration, this is true. Their general discussion of survey applications, however, was Iimited to the use of the interview technique. Situations where the use of mail surveys with follow-up procedures might be feasible were not discussed. Prior experience, however, had indicated some possibilities.

For example, Barnes [10] had previously shown that for some planning situations informative use could be made of mail survey opinion data. In four different transportation and development studies covering fifteen planning regions in Connecticut, Barnes and his associates conducted four sample surveys, one by interview and three procedurally different by mail. The purpose of those 
surveys was to investigate the resident's general attitudes and preferences concerning their towns and the State as well as their residential, recreational, and leisure-time preferences: what they liked, what they disliked, and where they thought improvements should be made. From these surveys, Barnes found that the responses obtained by mail were satisfactory for their survey purpose and, in some instances, better than those received by direct questioning.

The mail approach, however, has to be considered with the use of follow-up procedures or in combination with other methods to obtain acceptable return rates. For example, one of the surveys done by Barnes secured 71 percent return for a personally delivered questionnaire with three follow-ups, two by mail and one by telephone. This return rate was considered acceptable for the survey purpose. In the other two surveys, just mail follow-ups were used, and they obtained only 49 and 39 percent return. In most mail surveys, follow-ups by mail reduce in their effectiveness after several waves. Usually, other methods are necessary to obtain further returns. The methods most typically used are the telephone and personal interview.

For example, Hochstim [11] compared the use of mail questionnaires, telephone interviews, and personal visits for a survey of health and ways of living. In a series of experiments with various combinations of these methods, 
he investigated three strategies using identical questionnaires with independent but comparable probability samples. Each strategy combined mail, telephone, and interview methods in varying proportions depending on which technique was used first and therefore obtained the bulk of responses. The overall returns for these three strategies for two different studies were comparable as shown in Table 1.

Table 1 - Return Rate for Different Collection Strategies* Percent Return by Strategy

Study

1

2
Mail

88

89
Telephone

91

94
Interview

93

96

*Source: Reference [11]

These surveys sought factual data about respondents and self-evaluations of their present state of health which made the questionnaire an easy one to answer. The interview with mail and telephone followups was over twice as costly as the other two method combinations, while the strategy using mail initially was the least expensive.

Combining the mail technique with other methods has received recent attention for planning situations requiring objective data. At the time of this writing, the U. S. Bureau of the Census reported the results of an area 
travel survey using the above approach in Connecticut [12]. The study compared the combined use of a mail survey with telephone and interview follow-ups with a traditionally conducted home interview survey. Both surveys covered eleven towns, or cities, in Connecticut which ranged from 800 to 133,000 in population. The total survey return rates for both survey approaches are shown in Table 2 .

\section{Table 2 - Returns for a Travel Survey By Mail and Interview*}

\begin{tabular}{|c|c|c|c|c|c|}
\hline Method & $\begin{array}{l}\text { Sample } \\
\text { Size }\end{array}$ & $\begin{array}{l}\text { Total } \\
\text { Usable } \\
\text { Response }\end{array}$ & Percent & Vacancies & $\begin{array}{l}\text { Other } \\
\text { Un- } \\
\text { usable }\end{array}$ \\
\hline Interview & 400 & 81 & 6.3 & 3.0 & 9.7 \\
\hline $\begin{array}{l}\text { with } \\
\text { low-ups }\end{array}$ & 2,503 & 79 & 7.8 & 4.2 & 9.0 \\
\hline
\end{tabular}

*Source: Reference [12]

The study did conclude that the mail approach appeared to be sound even though it would not likely replace the traditional home interview.

As previously stated, the mail technique has several drawbacks which prevents its use in many situations. In some survey situations, however, response problems can be coped with by using the technique in combination with other methods. Even though the mailed questionnaire is limited in its ability to collect subjective data, this does not necessarily mean that it couldn't be effectively 
used in some planning situations. The advantages of the economy involved with mail could make surveys a more frequently considered alternative for obtaining public input. The limited experience, however, of using mail for planning surveys still leaves many questions about its feasibility. This research was directed towards obtaining information to help answer some of these questions.

\section{Past Methodological Research}

Social science research has made wide use of the mail survey technique. In conjunction with this use, there have been methodological studies to provide information to help assess the use of the technique for various survey purposes and target populations. Many of these studies have uncovered the methodological factors which can affect response rates to mailed questionnaires. Others have considered the characteristics of the respondents and non-respondents to mail surveys to help assess the response biases which might exist in a given survey's results. The methodological details and procedures which have been found to affect response rates most likely will hold true for applications in planning. The characteristics of respondents and non-respondents to a mailed planning survey, however, may not be completely the same as for other surveys since past mail research has also shown that the target populations interest in the survey subject matter is a primary determinant of response. The 
difference in survey subject matter was a primary consideration in the conduct of this study. For this reason, the role of survey subject matter will be further discussed after a brief review of the methodological details which can affect mail response rates.

\section{Factors Affecting Response}

Some of the factors which have been found to affect initial response to mail surveys are sponsor, questionnaire length, type of cover letter, type of questions, and method of return. Generally speaking, sponsors which are well known to the target population, and in their favor, are more likely to induce better return rates. On the question of length, the belief that mail questionnaires must be short was challenged some time ago by $\mathrm{Clausen}$ and Ford [13] when they obtained a larger initial response from a multiphasic questionnaire than they obtained by a shorter, single subject questionnaire, 42 percent versus 23 percent, respectively. Since then, other studies have shown that if the questionnaire is to be short, the shorter the better, and when the questionnaire is over approximately 10 pages, length may cease to be a factor [9], [14]. The cover letter plays an important role in securing response since it is used to introduce the survey purpose and sponsor along with the appeal for cooperation. Champion and Sear [15] compared the use of egotistic and altruistic types of appeal in cover letters. 
They found egotistic appeals induced slightly more returns than an altruistic one for lower SES groups, whereas altruistic appeals were slightly favored by higher SES groups. The type of questions asked can also affect response rates. Questions asking for objective information which can be easily checked or filled-in usually receive a better response than those asking for subjective information [9], [16]. Method of return can also have an effect. A regular stamped envelope has been shown to induce more returns than a business reply [17] or a machine stamped [15] envelope. Even though the effect of any one of these factors may not be relatively large, overall attention to these details can substantially improve mail response rates.

As previously mentioned, past mail research has shown that survey subject matter can be a determining factor in the response to mailed questionnaires [18], [19]. The subject matter of most planning surveys conducted for informative purposes is likely to be different than that associated with past social science research. Opinion surveys in the planning context are likely to seek residents attitudes, opinions, or suggestions about mostly their physical environments. This difference in subject matter would not necessarily make the overall return rates any more, or less, than surveys with subject matter of a sociological nature. However, the characteristics of 
respondents and non-respondents to a planning survey may not be the same because of the interest variable. With the exception of the component variables of SES, generalizations from past studies on likely respondent and nonrespondent characteristics may not hold true. Furthermore, the target populations from which planners might seek survey data are likely to be defined by some geographical boundary or by being users of a particular facility or service. These publics might be more homogeneous with respect to such variables as residence time, dwelling unit type, car ownership, etc. than they are on age, sex, race, education, or income. But even on the typical sociodemographic characteristics, no studies seem to have been made for determining the respondents and non-respondents to a mailed planning questionnaire. This information would not only be helpful in assessing the mail approach for different planning publics, but it would also help assess how crucial the eventual non-response is for affective attitude and opinion survey data of urban residents reactions to their environments [19].

Determining the characteristics of the respondents and non-respondents to a mailed planning survey was chosen as one of the study objectives on the above considerations.

\section{Follow-up Procedures}

As exemplified by previously cited studies, both mail and non-mail follow-up procedures are typically used with 
mail surveys. The type and number of follow-ups used varies from one survey to another depending on the survey's purpose, budget, and accuracy requirements. Some of the typical mail procedures which have been used are additional mailings of the questionnaire, reminder cards, letters, or telegrams, and special mail deliveries. The telephone call and the interview follow-ups have been the most frequently used non-mail procedures. Combining these procedures in a selected data collection approach can reduce survey costs and non-response. Some evaluative studies have been made of such combinations to assess the relative cost and contribution of different follow-up procedures.

In a recent study, Hochstim and Athanosopoulos [14] evaluated the use of a personally delivered mail questionnaire with three follow-ups, a reminder letter, telegram, and an interview. The survey was a longitudinal study of health and ways of living. Starting with a completely enumerated sample of a community population, they were able to accurately determine the contribution of the follow-up procedures to the sample estimates of the population on several characteristics. A comparison of the returns after the mail portion with the enumeration on fourteen characteristics of the population showed that the sample return estimates of these characteristics were all within two percentage points of the enumeration. The 
total return by mail was 70 percent which contributed to the small difference found between the sample estimates and the enumeration. The interview follow-up achieved an additional return of 14 percent. The interview was particularly effective for improving the sample estimates on race and SES. The interview follow-up returns obtained an over-representation of the non-white and the low SES populations. The per questionnaire costs for the mail and interview portions were $\$ 4.56$ and $\$ 13.65$, respectively, when the cost of the initial enumeration was not considered.

Data on the cost and contribution of follow-up procedures for a mailed planning survey are limited. In the aforecited attitude surveys by Barnes, one survey was conducted with both a mail and telephone follow-up to achieve 71 percent return to a mailed questionnaire which was personally delivered during a home interview survey. The data collection costs for the mail portion were reported to be 65 cents per return. However, the overall data collection costs for the survey and the cost and contribution of the telephone call follow-up were not reported.

In the previously mentioned area travel survey study by the Census Bureau, the overall cost and return rates of a mailed questionnaire with telephone and personal interview follow-ups were reported. For the total survey 
covering eight communities, 39 percent of the returns were by mail, 29 percent were obtained by telephone interviews, and 11 percent by personal interview. Only the overall cost for the survey was reported, $\$ 2.10$ per return. A home interview survey conducted in the same study cost $\$ 7.40$ per return.

Cost figures must be cautiously considered because of the many factors which can vary between surveys. Even so, the results of Hochstim and Athanosopoulos and those of the above study suggest an economic advantage of surveys combining mail with other follow-up procedures of about 3 to 1 over complete interview surveys.

Before a planning director can decide on what combination of follow-up approaches to use, he must consider how much additional time, money, and effort (at taxpayer's expense), he can justify to obtain additional returns. The level of effort will primarily depend on how crucial the non-response would be to the substantive opinion data and its intended use. However, as indicated previously, such information is lacking because of the limited experience of applying the mail technique to collect subjective opinions in planning studies. Furthermore, information about the relative merits of different follow-up procedures on cost and contribution for improving sample returns, in both number and accuracy, is still limited for planning applications. 
On the basis of these considerations, the other primary objective chosen for this research was to determine the cost and contribution of mail, telephone, and personal follow-ups to a mailed questionnaire to obtain further information which could help assess their use in planning survey applications. 


\section{CHAPTER III}

\section{STUDY DESIGN}

The general design of this study was to determine the characteristics of the respondents and non-respondents to a mail survey and to evaluate the cost and contribution of follow-up procedures. The approach was similar to that used by Hochstim and Athanasopoulos. Empirically, individual and household characteristics would be determined for the respondents and household characteristics for the non-respondents. Follow-up procedures would be considered for their cost per return, number of returns, and how much they improved the sample estimates of the population on selected characteristics. The analysis would consist basically of determining any characteristic differences between respondents and non-respondents and descriptively comparing the opinion data for different population subgroups.

\section{Study Population}

The population for this study was the resident households within the corporate city limits of Lafayette and West Lafayette, Indiana. The use of the local population was based on several considerations in addition to the 
convenience of location. At the time this study was initiated, a home interview travel survey was being conducted which covered both cities and the surrounding county. Available from this survey was an accurate sampling frame of households which could be utilized to reduce the research costs, and also, to allow a complete enumeration of the study sample on household characteristics. Furthermore, the substantive opinion data could be made available to the transportation and development study.

The disadvantage of using the local population was its being a University town with the associated factors that make it somewhat atypical of other communities. Also, area residents had most 1 ikely been surveyed and researched frequently by University research or class projects. These disadvantages, however, were not considered critical to the study's purpose.

\section{Selected Follow-up Procedures}

Four follow-ups were chosen for use after an initially mailed questionnaire. Two mail follow-ups and two non-mail follow-ups were selected. The two mail follow-ups were a reminder post card and an additional mailing of the questionnaire, cover letter and return envelope. The other two follow-ups were a telephone call reminder and a simplified personal contact.

The above follow-ups were selected for various reasons. The post card reminder was more simple and economical than a reminder letter and comparably as effective [20]. An 
additional mailing of the questionnaire was preferred over the use of just another mail reminder because it would allow those non-respondents who might have thrown away the original questionnaire another opportunity to respond. The telephone call reminder is often used, and as discussed previously, information on its cost and contribution is limited for planning survey applications.

The interview method has been shown to be the most costly and the most effective for obtaining returns. Existing information on the cost and likely contribution of the interview method can be used to assess its use as a follow-up to mailed planning surveys. A re-evaluation of the interview follow-up was not expected to provide enough new information to warrant the cost in time and manpower since its effectiveness was not likely to be affected by the planning survey subject matter.

A simplified personal follow-up was selected for the possible savings in time and labor for its conduct. Nonresponding households would be personally visited only once. At those households where somebody was found at home, they would be given the option to either selfadminister the questionnaire in the presence of the collector or complete the questionnaire at their convenience and return it by mail. For those households where nobody was at thome, the questionnaire, cover letter, and return envelope would be left at the door to salvage the visit 
with at least another reminder. The time required to canvass a given number of households by this approach was expected to be less than that required by interviews even though the travel time was likely to be the same. Also, it was assumed that to conduct such an approach, no specially trained personnel would be required. Planning agencies, then, might save on both time and labor since untrained personnel could be used or even perhaps the help of community service organization volunteers might be obtained to conduct such a follow-up. The cost and contribution of the above approach were expected to range between that of the telephone call and the interview follow-ups. In those situations where the accuracy of the returns is not as critical to the informative use of the opinion data as the planning director's budget, this simple approach could possibly offer another follow-up alternative.

Selected Procedure and Characteristics

Procedural Design

A two stage design was selected to evaluate the mail and non-mail follow-ups. The basic reason for selecting this type of design was to evaluate the mail follow-ups in the same way that they would be used in practice and still allow a separate comparison of the telephone and personal follow-ups. The procedure would be as follows. 
After the initial mailing, the mail follow-ups would be successively sent to the non-respondent households. After the mail-out portion was completed, the remaining nonrespondent households would be divided into two groups with one to receive a telephone call follow-up, and the other, a personal follow-up. By using two treatment groups, a comparative evaluation could be made of using either the telephone or the personal follow-up directly after the mail portion of a survey.

\section{Individual and Household Characteristics}

Several considerations were made in selecting what individual and household characteristics were to be obtained. For comparative purposes, characteristics which had been used in past mail research were desired. Of these characteristics, those having a possible association with the interest in the survey subject matter were chosen for descriptive comparisons of the opinion data. The household characteristics were also selected on the basis of their availability for the study population from other data sources.

The individual characteristics selected were: age, sex, education, and resident time. The household characteristics chosen were: city location, occupation of household "head", family composition, number of persons living in the household, home ownership, and dwelling unit structure type. 
The basic analytical approach for considering the above characteristics with respect to survey response and the opinion data was to discover any major differences. For this reason, broad nominal classifications of these characteristics were used for describing the respondents and non-respondents and for the opinion data comparisons.

\section{Questionnaire Design}

\section{Subject Matter}

There exists a wide range of community subject areas about which planners would be interested in obtaining resident's opinions. Answers to the question of community needs were considered to be of basic informative use. For this reason, the questionnaire design was focused on the question of community improvements. A choice was made to obtain resident's suggestions for improvements in facilities, services, or conditions over some major categories of community concern, such as, health care, housing, education, transportation, recreation, etc.

The above choice was based on several considerations. Planning is directly or indirectly concerned with the provision of most community facilities and services. Resident's opinions about the same could be useful in locating problem situations needing further study. Also, by using enough major categories to cover most subject areas of community concern, the possible response biases 
from the variation of public interest and awareness in different subject areas could be attenuated. The scope of these categories would, however, prevent an in-depth coverage with a short questionnaire.

Three basic questions at the community level were selected to obtain resident's opinions about improving the community. These were:

(1) in which major categories did they seem to think the community needed the most improvement,

(2) what specific facilities, services, or conditions would they like to see improved, and

(3) how did they feel about the relative importance of several community projects which wore under current consideration.

\section{Question Formats}

As mentioned previously, the type of questions used in a mail questionnaire can affect response rates. It is generally recommended in self-administered questionnaires to use mostly "closed" form type of questions such as checklists, rating scales, or inventories to make responding easier [16]. Considering the subject matter and the desire for a short questionnaire, a closed form structure could have resulted in a questionnaire composed of several "omnibus" checklists of facilities, services, and conditions for evaluative ratings. Such a design was not generally recommended, either, because it could produce 
superficial responses and respondent boredom. Furthermore, it would have required prejudgement of what particular facilities, services, or conditions should be listed, To mitigate, one open and two closed forms were chosen. For question (2) above, the freedom of an open-ended form would obtain more information, and for questions (1) and (3), a closed form was considered adequate.

The design for question (1) presented a problem. The categories which were considered for covering the major subject areas were "global" within themselves. To ask residents to comparatively evaluate or rank ten or twelve of these major subject areas on the dimension of "needing the most improvement" would have required the assumption that they were comprehensively aware enough to do so. On the other hand, a resident was 1 ikely to regard some areas to be in more need of improvement than others from his knowledge of the community. Asking the respondent to indicate these areas by free selection was considered a more realistic approach than asking for a complete ranking or evaluation.

For question (2), several open-ended question forms were considered which had been used in past mail and interview surveys to obtain free responses of resident's dissatisfactions with their community. After reviewing the kinds of responses elicited by some of these questions, a more directed question was desired to obtain more specific 
responses and possibly over a wider range of subject areas. The pilot and pre-test was primarily devoted to developing such a question.

The approach taken was to use a list of major categories to suggest to the respondents what subject areas of the community to consider. Then, within any of these subject areas, to let them freely suggest any improvements that they would like to see made in facilities, services, or conditions. These suggestions for improvements might then indicate not only the object of their dissatisfaction but also, what they would like to see done about it.

To develop a list of major categories for this purpose, and for use later in question (1), several recent community goal studies were examined to determine typical areas of community concern [21], [22], [23], [24]. The categories chosen and the initial pilot-test design for the category-type question are shown in Appendix A. Even though they are not completely exclusive of each other, the categories cover most major areas of community concern. There was a question as to whether these categories would be meaningful to the respondents. This concern influenced the format design to allow the respondents to code their own open-ended responses by major category. In this way, a test could be made of how much agreement there was between the respondent's reference frame and that which might be used for coding the responses for analysis. 
Furthermore, since many suggestions for improvements might not be exclusively covered by a single category, the respondent's categorical assignment would help indicate to which aspect of a given facility, service, or condition he was reacting.

\section{Pilot-Test}

The primary purpose of the pilot test was to see what kind of responses the category-type question elicited, both in number and content. For this test, the category question was "sandwiched" between two sets of general questions: one set about the "likes" and "dislikes" at the community level, and another set at the neighborhood level. These questions had the following open-ended form:

"What features of (the Greater Lafayette Area/your neighborhood) do you (like/dislike) the most?

The community level question was used to see what general areas of possible dissatisfactions the category question didn't cover. The general questions at the neighborhood level were used to help keep responses about neighborhood problems from being given for the category question.

For the pilot test, forty-one households were selected from a previous study population on the basis of the education of its adult members. The households had two married adults within the same range of years of education completed. The pilot questionnaire, cover letter, and return envelope were mailed to these households with a 
post card follow-up seven days later. The total number of respondents was twenty. Of these twenty respondents, four had less than a high school education, five had graduated from college, and eleven were college graduates. Their responses to the general "dislikes" and the category type question were edited and counted.

A comparison between the responses to the general "dislikes" question about the community and the category type question could not be treated as being independent. Even so, a comparison did indicate some differences in both number and content. The average number of responses to the category question was 3.9 versus 2.2 for the general "dislikes" question. Concerning content, there was some overlap between the questions, but qualitatively, the responses to the category question were more specifically directed. These findings had to be taken tentatively since the intended difference between the two questions may not have been discernible by the respondents and there could have been interaction between the two questions. Nevertheless, the category-type question seemed to elicit more specific comments from the respondents.

A review of the responses showed that the category question did not receive as many responses in the general social and community appearance categories as did the 
general "dislikes" question. In the social category, the specific responses were mostly directed at dissatisfactions with other people in the community, e.g., their attitudes, how they lived, their child rearing practices, etc., which are not directly affected by planning. Community appearance, however, is a typical consideration in the planning of the physical environment.

Another purpose of the pilot test was to see how meaningful the "global" category titles were to the respondents. A check was made on how they categorically assigned their responses. Using three judges, only seven out of the seventy-nine total responses to the category question were classified in different categories than those given by the respondents. Even with this unexpected agreement, two changes were made to aid the coding and to provide more "meaningful" titles to the respondents before the pre-test. These changes were:

(1) replacing the Health Care and Sanitation category with two categories, Health Care and Environmental Protection, the former intended to cover those responses related to medical facilities, services, personnel, costs, etc., and the latter to cover sanitary conditions, pollution, etc., and

(2) combining Recreation and Cultural Activities into one category.

Furthermore, since the pilot test consisted of only 20 
respondents, the findings and changes were considered tentative.

\section{Pre-Test}

The purpose of the pre-test was to further evaluate the category question and to test the major category checklist question and the evaluative checklist of community projects. The formats used for these latter two questions are shown in Appendix $B$. In the pre-test schedule, the category question was preceded by the major category checklist and followed by the checklist of specific community projects.

For the pre-test, an area probability sample of the dwelling unit population within the corporate limits of Lafayette and West Lafayette was taken. The sampling frame and procedure used were the same as in the final survey. The details of the sampling procedure are given in Chapter IV. The only difference was that the pre-test sample was smaller than that of the final survey. The pre-test sample size was 234 dwelling units. Dwelling units outside the corporate limits, in fraternities, sororities and co-op houses, and with incomplete addresses were excluded.

A five-page pre-test questionnaire was mailed to these 234 units along with a cover letter (Appendix B) and return envelope. The questionnaire was multilithed on white paper with both mailing and return envelopes hand 
stamped with first class postage. Twenty-one of the questionnaires were returned by the post office, marked unclaimed, no such street number, vacant lot, etc., resulting in 223 delivered questionnaires. The questionnaires contained a conspicuous code number on the frong page to determine what households failed to respond. Seven days after the initial mailing, a post card reminder, as shown in Figure $\mathrm{C} 6$ was mailed to the non-responding households. The cut-off time was three weeks after the initial mailing.

The total response rate was 31 percent. The mean age of the respondents was 46 years old, and their mean resident time in the area was 26 years. Of the 68 respondents, 10.2 percent had less than a high school education, 53.0 percent were high school graduates only, and 36.8 percent were college graduates.

For the major category checklist, many respondents checked less than five categories with the average being 4.3 categories. This result suggested that asking the respondents to check five categories might be too many. To aid discrimination, it was decided to ask the respondents to check only three categories in the final survey.

The responses to the category question asking for specific suggestions for improvements were edited and coded by major and minor categories. Three "judges" participated in the editing and coding of the verbatim 
responses. Many responses consisted of several different suggestions. These were isolated and counted as separate suggestions. There was a considerable amount of judgement involved in assigning a few of these specific suggestions to one major category or another. In most instances, however, the categories were a meaningful coding scheme for both the respondents and the judges.

The total response to the category question averaged to 4.2 suggested improvements per respondent which was slightly higher than what was obtained in the pilot test. On the basis of both the pilot and pre-test results, the response spaces provided for the category question was reduced to four for the final questionnaire.

In Table 3 is shown the relative frequency of response for both the checklist question and the category question by major category for the pre-test returns. As Table 3 shows, there was a high degree of similarity between the response distributions to the two questions over most of the major categories. The major differences were in three categories, Environmental Protection, Local Economy, and Transportation and Public Utilities. It was the intention of the questionnaire design to force the respondent to consider the question of what major categories 'needed the most improvement" at both the general and specific levels. Methodologically, the two questions cannot be treated as independent stimuli because of the possible 
TABLE 3. Pre-Test Responses to the General and Specific Questions By Major Category

Percent

Genera1

Checklist

11.8

5.9

13.1

6.3

6.6

10.1

8.5

3.7

7.7

10.0

14.7

1.6

100.0

(272)
Specific

Suggestions

13.1

6.6

7.4

5.1

6.2

5.8

9.7

5.1

8.6

9.1

20.5

2.7

99.9

(257)

\section{Major Category}

Community Appearance

Education

Environmental Protection

Health Care

Housing

Local Economy

Local Government

Public Assistance

Public Safety

Recreation and Cultural Activities

Transportation and Public Utilities

Other 
interaction effects, i.e., the respondent's answer to one question affecting his answer to the other. For this reason, it was considered methodologically necessary to treat the response distributions to these two questions as component indicators of the answer to "what major categories were most in need of improvement" from the respondent's frame of reference. This interpretation would then be qualified by using a consistency check of each respondent's answers to these two questions in the final survey.

The addition of the Community Appearance and Environmental Protection categories was reinforced by the pretest responses. For the Transportation and Public Utilities category, the majority of the suggested improvements fell under Transportation. For this reason the Transportation and Public Utilities category was split into two separate categories for the final list. Also, for the final list, it was necessary to drop Cultural Activities because it created a physical space problem when combined with Recreation and it had received only a few specific comments. Also, categorical assignments had indicated that many people associated cultural activities with recreation, and it was likely that the Recreation category would "catch" these comments in the final survey.

The evaluative checklist question of current community projects was basically without problems in the pre-test. The only change for the final design was a 
reduction in the number items to ease the responding task.

\section{Final Design}

Shown in Appendix $C$ are the four pages of the final questionnaire design. These were printed on one $81 / 2 x$ 14 inch sheet of white paper with black ink. The page was then folded in booklet form to give the questionnaire a "shorter" $100 \mathrm{k}$.

For the final design, several changes were made in the questions and their wording. Question (4) was changed slightly from the pre-test to make it more direct. The question about "how soon" on each specific suggestion in the pre-test design was considered too complicated for the respondents and was eliminated. As a substitute, question (5b) was used in the final design to obtain some indication of what categories received the most number of "urgently" suggested improvements. For question (6), the specific item list was provided by the director of the local planning agency. To obtain suggestions for improvement at the neighborhood level, question (7) was chosen as a replacement for the general question about neighborhood "dislikes". Question (7) is a slight modification of one used by Richards [25] to elicit more specific suggestions. Question (3) was retained for the purpose of providing a positive counter-balance to questions (4) and (5). 


\section{Other Considerations}

Attention was given in the study design to what sponsor, cover letter, coding procedure, and post card reminder could be used.

Using Purdue University as the sponsor of the survey and informing the respondents that the survey was a research project was considered atypical of one sponsored by a planning agency. The intervening factor was that local residents had been surveyed and researched frequently by projects associated with the University. To provide some control for this factor, the survey was titled as a "Community Improvement Study", and the address of the Lafayette Transportation and Development Study Office was used on the return envelopes. The heading used on the mailing envelope and the cover letter was "Community Improvement Study" with the street address of the above office. Approval was received for the use of the office address.

The cover letter informed the potential respondents that the information they gave would be made available to the transportation and development study. Also, since the survey sample was a sub-sample of the study population used for the transportation and development study, the "tie-in" also served the purpose of telling the respondents how they came to be selected. The cover letter which was used is shown in Figure C5. Technically speaking, it does not state a sponsoring organization. 
The coding procedure for determining what households had responded was changed for the final survey. In the pilot test and pre-test, the case number was written in the upper right hand corner on the front page of the questionnaire. The use of a conspicuous code number was considered as a possible intervening factor in some potential respondents might abstain in fear of being "identified". Since the primary objectives of this study depended on accurately determining the respondent and non-respondent households, concealing the code number was necessary to prevent an interaction with response. The procedure selected was to put the case number in the deep inside corner of the return envelope. Such an approach ran the risk of respondents using other than the provided envelope. However, it was considered simpler and less likely of detection than other coding schemes.

The wording of the post card reminder used for the first mail follow-up was similar to that used by Nichols and Meyer [26], and is shown in Figure $C 6$. 


\section{CHAPTER IV}

\section{SAMPLING PROCEDURES}

\section{Initial Sample}

As stated previously, the population of dwelling units within the corporate limits of Lafayette and West Lafayette was the study.population. However, student fraternity, sorority, and co-op houses had to be excluded because these larger units posed sampling problems and their household characteristics could also be atypical.

To reduce the research costs, the sample for this study was taken from the list of dwelling units selected for interviewing for the Greater Lafayette Transportation and Development Study. The population for that study was all the dwelling units in Tippecanoe County. From an updated field listing of all dwelling units compiled during a land-use inventory one year prior, the above study selected a systematic sample of every eighth dwelling unit according to the following procedure:

(1) divided the county into zones and subzones on the basis of traffic generation;

(2) within each subzone, the lowest block number was the starting block; 
(3) on each block, the lowest parcel number was the starting parcel for selecting the first dwelling unit ;

(4) the block was then traversed counter-clockwise with every eighth dwelling unit being selected; and

(5) the next highest block number was then found and steps (3) and (4) were repeated.

With the study objectives and the practical constraints in mind, an initial sample size of approximately 500 dwelling units for this study was considered large enough to keep the sample estimates of the population proportions on most characteristics within 10 percent at the 95 percent confidence level [27].

Using the aforementioned list, with a random start, every fifth dwelling unit address was selected resulting in 886 dwelling units. Of these, 293 units were found to be outside the city limits. The resulting list was then an area probability sample of the dwelling unit population within the city limits. Then, all cases which were dwelling units in fraternity, sorority, and co-op houses were excluded. Sixtéen other addresses were found to be incomplete and were excluded. The resulting sample size for the initial mailing was 489 dwelling units.

The dwelling units which refused the travel survey home interview were retained in the sample because their 
exclusion would have biased the initial sample on potential refusals. No replacement was to be made of any dwelling unit which turned out to be vacant or might have been torn down in the past year.

The initial mailing to this sample would solicit any adult member of the dwelling unit to be the respondent. Although this would present a sampling bias with respect to the population of individuals, it was still the practical approach that a planning agency might use in a mail survey of the general public.

\section{Non-Mail Follow-Up Groups}

Several considerations were made in selecting the method for dividing the non-respondents to the mail-out portion into two groups to receive either the telephone or personal follow-up treatments. Matching the two groups on all household characteristics was not considered possible. Furthermore, randomly assigning cases to two groups posed the possibility of the two groups being significantly dissimilar on an important variable. As a compromise, the two groups were matched on city location.

City location was chosen for several reasons. The populations of the two cities differed on some characteristics. For example, in the 1960 Census, the reported median years of education for the populations of West Lafayette and Lafayette was 16 years plus and 11.3 years, respectively. The educational difference could not 
be completely attributed to the larger proportion of University students living in West Lafayette. The 1960 Census did not count students as part of the city population unless they were permanent residents. With a likely association between education and city, controlling on the city location would also provide some control on SES. Also, differences between the two cities in social, economic, political, and physical conditions could affect a resident's level of interest in the improvement of the entire area.

The sampling procedure was to utilize the originally assigned case numbers to provide some further control on areal location. The non-respondent cases after the mailout portion would be put in numerical order of their case numbers. Case numbers had been originally assigned according to areal location by zone as described previously. With cases in this order, a systematic sample with the first case randomly assigned to one of the two groups would result in no greater difference than one case per city between the two groups. Furthermore, since the case numbers were assigned within zones, the non-respondent cases for those zones having two or more cases would be approximately split between the two groups depending on whether there was an even or odd number of cases in the zone. Even though the cases would not likely be randomly distributed by zone, the above procedure would provide as 
much control as possible with respect to other household characteristics, such as dwelling unit type, which might be somewhat homogeneous within a given areal zone. For these reasons, the above procedure was selected rather than a random sample controlling on city location alone. After the two groups had been selected they would then be arbitrarily assigned to the follow-up treatments. 


\section{CHAPTER V \\ DATA COLLECTION}

The data collection procedure was conducted as was previously outlined. The survey was taken during the month of October and the first week of November. Accurate accounts of the material and labor costs for each procedural stage were kept. The execution of each procedural stage will be briefly discussed.

\section{Mail-Out Portion}

The questionnaire, cover letter, and return envelope were mailed with hand stamped, first-class postage to the 489 selected dwelling unit addresses. Thirty-five of the initial mailings were undelivered for various reasons such as; vacant, no such number, or more than one dwelling unit existed at a given address. The addresses of these were double checked. All were found to agree with those given on the initial list. These addresses were then removed from the sample and excluded from further consideration. These exclusions resulted in 454 questionnaires in the initial distribution.

A card file was used to keep a daily record of all returns. Six days after the initial mailing, post card reminders were mailed to all dwelling units which hadn't 
responded. The six days included a weekend which allowed four and one-half mailing days for the first wave return. Eleven days after the post card reminder, a second complete mailing of the same questionnaire with cover letter and return envelope was made to the non-responding households. Ten days after the second mailing of the questionnaire, the mail portion of the survey was ended.

The returns were then examined for their usability. A return was classified as usable if the respondent answered at least one of the substantive opinion questions. Only five of the questionnaires received were unusable. These were classified as non-response.

After the mail-out portion of the survey, there remained 209 non-respondent cases. These non-respondent cases were put in numerical order of their case numbers. $\Lambda$ systematic sampling of the cases into two groups was then made as previously discussed in Chapter IV. The follow-up treatments were then arbitrarily assigned.

\section{Telephone Follow-Up}

The 1971 telephone directory and the 1971 city directory for the cities of Lafayette and West Lafayette were used to obtain the telephone numbers of the case addresses. Those addresses for which no number could be found in either directory were treated as having no telephone. No further effort was made to obtain unlisted numbers on the judgement that most planning agencies would rely on only public data sources. 
The telephone reminder calls were started three days after the cut-off date of the mail portion of the survey. The first round of calls was made during a Sunday afternoon and evening. On the following Monday evening, a second round of calls was made to those households where there had been no answer previously. Two days later, a third round of calls was made in the morning, and a final attempt was made in the evening to those yet to be contacted.

The reminder call consisted of telling the household member the following in an informal manner:

(1) the caller's name and his association with the "Community Improvement Study",

(2) the call was part of a check being made to insure that all households selected for the survey had received a questionnaire in the mail,

(3) the survey information was going to be made available to the Lafayette Transportation and Development Study, and

(4) the household member was then asked if they had received the questionnaire.

The subsequent discussion then varied with the household member's response. The majority of the people responded in a manner which reflected a sense of "guilt" as if they had neglected a civic duty by not having returned the questionnaire. These responses were of the general form 
of some reason being given for not having been able to complete the questionnaire as yet, but it would be filled out soon and returned. In other instances, some people answered that they had received the questionnaire with no further comments. In either of the above cases, a followup plea was made for the questionnaire to be completed at the earliest convenience and returned by mail. For those households where the questionnaire had been reported as lost,or thrown away, another questionnaire was mailed.

Not all of the households for which a number was listed could be contacted by phone. Some of the telephone numbers obtained from the directories were incorrect due to moves, or the telephone was out of service. Of the 104 cases in the subsample, 12 households had no telephone. The numbers obtained for 6 cases were incorrect, and 7 other cases had telephones out of service. This resulted in 79 cases having telephones of which 67 were contacted. Thus, on 1 y 65 percent of the subsample was reached by telephone. This percentage was lower than what had been expected. The use of the telephone, however, has to be considered with this associated limitation.

\section{Personal Fol1ow-Up}

The canvass of the subsample of households was started five days after the cut-off date of the mail-out portion of the survey. Al1 105 dwelling unit addresses in the subsample were visited one time by the author and a male 
assistant. The visits were made between the hours of 10:00 a.m. and 4:30 p.m. over three consecutive weekdays. As stated previously, those households with someone at home and those without anybody home were to receive different treatments.

Originally, it had been planned to give the household member the option of either completing the questionnaire in the presence of the collectors or completing it at their convenience and returning it by mail. It became apparent however, after a few contacts that trained personnel would be required to tactfully induce a household member to interrupt their activity and complete the questionnaire on the spot. Pursuing this optional approach would have made the use of untrained personnel for this type of follow-up questionnable. For this reason, the approach at the remaining households was to only ask the household member to complete the questionnaire at their earliest convenience and return it by mail.

The conversational approach at those households where a personal contact was made was similar to what had been used with the telephone calls. As was the case in the telephone follow-up, most people contacted reflected a sense of "guilt" for not having completed the questionnaire. Where the questionnaire had been lost or thrown away, another one was left at the household. Before leaving, an additional plea was made for cooperation and prompt return of the questionnaire. 
For those households without anybody at home, the visit was partially salvaged with another reminder. A cover letter, questionnaire, and return envelope were left at the door. The cover letter which was used is shown in Figure C7.

\section{Non-Respondent Household Characteristics}

Five characteristics of the non-responding households were obtained. These characteristics were: the resident time and the occupation of the head of the household, the city location, the type of dwelling unit, and whether the dwelling unit was owned or being rented. The information for the latter three characteristics was obtained from the data collected in the Transportation and Development Study. The resident time and occupation of the head of the household were determined by using both the above study data and the 1970 and 1971 city directories. The procedure used for obtaining these two characteristics is described below. Using the city directories, the occupancy name of each non-responding address in 1970 and 1971 was checked. If the occupancy name was the same for both years, the time for the head of the household was taken from the Transportation Study data. Where the occupancy names were not the same the resident time was taken as less than one year. The occupation listed in the city directory was taken as that of the head of the household. In those cases where the occupation was not reported in the city directory 
and where the resident time was one year or more, the occupational data were taken from the Transportation Study data. The occupations were coded in the following categories :

(1) High SES - Professional, technical - Business managers, owners, officials, etc.

(2) Middle SES - Clerical, sales, craftsmen, foremen, and kindred workers.

(3) Low SES - Operatives, unskilled, service, domestic, and kindred workers.

(4) College students.

(5) Retired

The procedures used for determining the resident time and occupation likely resulted in several classification errors. These classification errors were not considered critical because the data were questionable for only a small number of cases and broad nominal categories were used. 
CHAPTER VI

RESULTS

The results of this study are presented in two parts. The methodological data obtained to evaluate the survey approach are discussed first. A summary presentation and discussion of the survey data collected comprises the second part. The data were compiled and analyzed with the computer using the Statistical Package for the Social Sciences [28] computer program.

\section{Methodological Data}

Initial Sample

The initial dwelling unit sample was checked for any serious bias with respect to the study population. In Table 4, the initial sample proportions on dwelling unit location, structure type, and tenure are compared with those reported for the study population in the 1970 Census of Housing. As Table 4 shows, the survey sample was proportionally about the same as the population on city location and slightly over-representative on single unit and rented dwellings. Even though these latter biases are very small all comparisons were made with the enumerated sample values to account for these slight differences. 
TABLE 4. Dwelling Unit Characteristics of Initial Sample

$\begin{array}{lcc}\text { Dwelling Units } & \begin{array}{c}\text { Survey } \\ \text { Sample } \\ (N=454)\end{array} & \begin{array}{l}1970^{*} \\ \text { Census } \\ (N=22,188)\end{array} \\ \begin{array}{lcc}71.8 \\ \text { W. Lafayette }\end{array} & 28.2 & 70.1 \\ 1 \text { unit structure } & 69.8 & 65.9 \\ 2 \text { or more units } & 30.2 & 34.5 \\ \text { Owned } & 59.7 & 62.2 \\ \text { Rented } & 39.2 & 37.8 \\ \text { Undetermined } & 1.1 & \end{array}$

*1970 Census of Housing

TABLE 5. Survey Response by Procedural Stage Number Return Percent of Rate of

No. Procedural Stage Number Returns (Percent) Total

1 Initial question$\begin{array}{lllll}\text { naire mailing } & 454 & 115 & 25.4 & 37.8\end{array}$

2 Post card re minder 339

$\begin{array}{lll}78 & 23.0 & 25.6\end{array}$

3 Second questionnaire mailing

261

47

18.0

15.5

4A Personal followup

105

40

38.1

13.2

4B Telephone followup

104

23.1

7.9

Al1 Stages

-. 304

$67.0 \quad 100.0$ 


\section{Returns}

The returns for each procedural stage are shown in Table 5. The overall return rate for the survey was 67 percent. The return to the mail-out portion was about what had been expected, 52.7 percent. The percent return after the post card reminder was higher than what had been expected from the pre-test results. The return rate for the first two waves was over 11 percent higher.than what was found in the pre-test, 42.5 versus 31.0 percent. Some of the improvements could have resulted from differences between the final survey and the pre-test, such as, improved questionnaire design, timing, or sponsor. The final questionnaire was shorter and had a better appearance than the pre-test form. In the final survey, the initial mailing and the post card reminder arrived on a Saturday and a Friday, respectively, whereas, for the pre-test, the arrivals were on a Tuesday and a Wednesday. The sponsor for the pre-test was the Civil Engineering Department of Purdue University, whereas the final survey had the previously discussed "obscured" sponsor. The difference in response rate was probably attributable to these factors although their relative contributions cannot be assessed.

The results of two previously cited studies were used as an external reference to check the inferred applicability of these results to other small communities. Table 6 shows the return rates of the mailed travel surveys done by the Census Bureau and the opinion surveys done by Barnes. The 
TABLE 6. Return Rates of Other Mailed Community Surveys

\begin{tabular}{|c|c|c|c|c|}
\hline City & $\begin{array}{l}\text { Population } \\
\text { (Persons) }\end{array}$ & $\begin{array}{l}\text { Sample } \\
\text { Size } \\
\text { (Dwelling } \\
\text { Units) } \\
\end{array}$ & $\begin{array}{l}\text { Initial } \\
\text { Mail-Out } \\
\text { Response }\end{array}$ & $\begin{array}{l}\text { Total } \\
\text { Mail-Out } \\
\text { Response }\end{array}$ \\
\hline \multicolumn{5}{|c|}{ Census Surveys ${ }^{1}$} \\
\hline New Haven & 133.543 & 1,013 & 23.4 & 33.2 \\
\hline West Haven & 51,216 & 339 & 33.3 & 43.9 \\
\hline Hamden & 49.169 & 313 & 42.7 & 54.0 \\
\hline East Haven & 24,660 & 151 & 33.6 & 42.3 \\
\hline North Haven & 22,186 & 128 & 30.5 & 49.2 \\
\hline
\end{tabular}

Barnes Surveys ${ }^{2}$

$\begin{array}{lllll}\text { (Regional) } & \ldots & 2,910 & \ldots & 39.9 \\ \text { (Regional) } & \ldots & 3,224 & \ldots & 49.9\end{array}$

$\begin{array}{lllll}\text { Lafayette }- & 64,112 & 454 & 39.4 & 52.7\end{array}$

West Lafayette

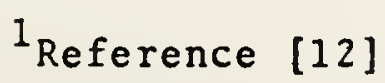

${ }^{2}$ Reference [10] 
Census surveys used the same mail follow-up treatments as this study, a reminder card and a second mailing of the questionnaire. The Barnes study used a reminder letter and a second mailing. The Census study sought more objective data and had a more well-known sponsor than either the Barnes surveys or this survey.

From the data shown in Table 6 , it would be reasonable to conclude that a mailed community survey having a planning related subject matter conducted with two mailed follow-ups is 1 ikely to obtain from 40 to 50 percent return in most communities. The return rate will vary, of course, with the effort a planning agency puts into a survey and the attention it gives to the methodological details. In most cases, however, additional follow-up efforts would have to be made to obtain survey response rates above 50 percent. After the mail-out portion of the survey was ended, 209 sample households had not responded. These households were separated into two groups for the telephone and personal follow-ups as previously explained. The dwelling unit characteristics of the two groups are shown in Table 7 for comparison. Very small differences existed between the two groups on the characteristics shown.

The telephone follow-up obtained 24 additional returns, or 23 percent of the sub-sample. The low percentage for the sub-sample is partially attributable to the fact that only 67 percent of the sub-sample households could be reached by phone. On the basis of the number contacted the return rate 
TABLE 7. Dwelling Unit Characteristics of Telephone and Personal Follow-Up Groups

Dwe11ing Units

Total

Lafayette

W. Lafayette

1 unit structure

2 or more units

Owned

Rented

Undetermined
Tel ephone

Fol1ow-Up

104

75

29

70

34

51

50

3
Persona 1

Fo11ow-Up

105

75

29

66

39

50

53

2 
was 36 percent. This return rate was twice that obtained for the second mailing (18 percent). For those contacted, the response rate was still lower than what had been expected. Voiced intention of cooperation by household members over the phone proved to be an unreliable criterion. The use of telephone reminder calls must be considered with the associated limitations of some households not having phones, someone not being at home, or having unlisted or disconnected numbers. The use of a third mailing to those households which cannot be reached by phone could be an effective supplement to this approach. Omitting the use of this third mailing was an oversight of this study.

The simplified personal follow-up obtained 40 additional returns, or 38 percent of the sub-sample. Fifty-two percent of the sub-sample households were personally contacted with the remainder having a reminder letter, questionnaire, and return envelope left at their door. The return rate for those households personally contacted was 40 percent, and for those not at home, 36 percent. Unexpectedly, both treatments were comparably effective. The impressions given by household members personally contacted caused an overexpectation of 1 ikely returns. On the other hand, the returns from those households receiving the notice of a visit and a questiomaire was not expected to have, as it did, a return rate higher than the second mailing of the mail-out portion of the survey. 
As a conjecture, notifying the households in the reminder letter that their household had been visited in a special effort to obtain their response probably induced responses which a third mailing of the questionnaire might not have obtained.

Conducting the above follow-up approach in the daytime working hours, as was done here, would result in a large percentage of households having nobody at home. However, the results here indicate that the effectiveness of the overall approach may not be seriously affected by this condition since a reminder notice was comparably effective to an actual contact. Also, short visits at households, using this simplified approach resulted in a canvassing rate of 9 households per hour.

There is no basis for stating whether or not the return rates for another application would be more or less than what was obtained here. Comparison with the mail-out return rates indicate that this approach would be more effective than an additional mail reminder while still not expending a great deal of time and money to obtain responses from reluctant households.

The use of either the telephone or personal follow-up after the mail-out portion is likely to be comparable on the basis of returns if the telephone follow-up is supplemented by a third mailing to the unreachable households. Both approaches, of course, could be used in a given survey with their relative costs determining the sequence of use. 


\section{$\operatorname{Cos} t s$}

Accurate accounts were made of all labor and material costs associated with each procedural stage of the data collection. In Table 8 are the cost accounts for each stage by items of expense. The initial sampling and listing of case addresses were charged to the initial mailing stage. As noted, labor time was converted at the rate of $\$ 3.00$ per hour.

The overall survey cost for data collection was $\$ 541$ with an average cost per return of $\$ 1.78$. As shown, the cost if only the personal follow-up had been used was $\$ 1.91$ on the basis of a projected overall return of 71 percent. If a telephone follow-up, supplemented by a third mailing, had been used, the overall return rate would likely have been comparable but somewhat lower in cost. On the basis of the cost and return data obtained, a similar survey combining the use of all these procedures for economy and effectiveness could be conducted as follows:

(1) initial mailing,

(2) post card reminder,

(3) second mailing,

(4) post card reminder,

(5) telephone call reminders supplemented by a third mailing of the questionnaire, cover letter, and return envelope, and

(6) a simplified personal follow-up. 


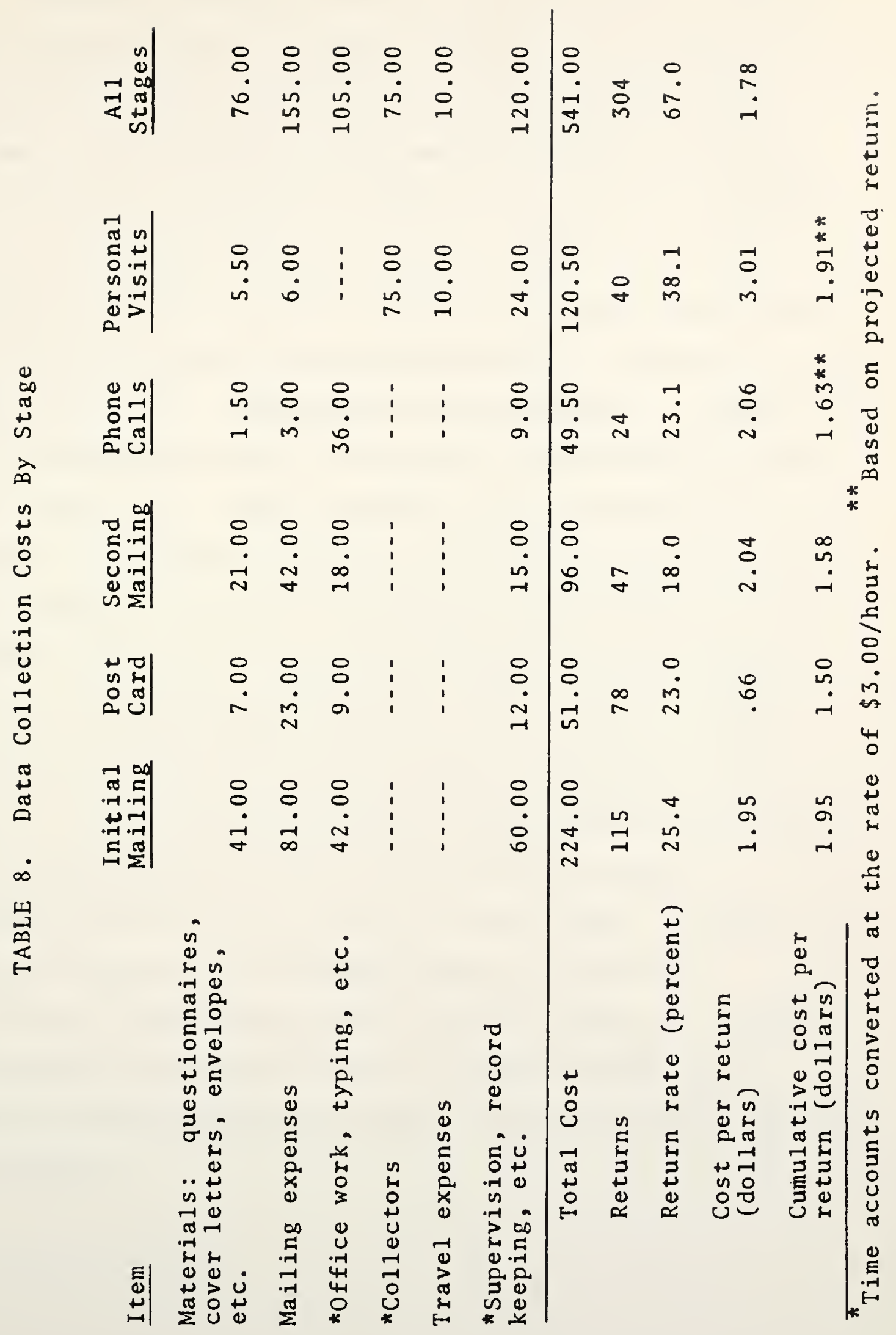


Whatever combined approach is selected for following up a mailed survey, a certain degree of non-response can be expected even when interview follow-ups are used. For example, the previously cited mail surveys by the Census were followed up by both telephone and personal interviews. The non-response to these surveys ranged from 17 to 24 percent. Similarly, the Hochstim and Athanosopoulos study still had 14 percent non-response after an interview follow-up. This same degree of non-response is typical of that expected in complete interview surveys which do not use substitution [29]. In most cases, approximately 15 percent non-response could be expected when typical follow up techniques are used. If a mailed survey obtained 50 percent return and a telephone reminder obtains another 15 to 20 percent approximately 40 to 50 percent of the remaining sample is still not likely to respond. The decrease in the expected return rates at the later followup stages makes the cost of the follow-up a more determining factor in its use at these stage. In some cases, combining the telephone call with the more economical simplified personal follow-up might be a more acceptable alternative than an interview follow-up in view of the expectedly low return rate and the high cost of interviews. 
Respondents and Non-Respondents

Comparisons of the survey respondents and non-respondents was basically to determine:

(1) how the survey respondents after each procedural stage compared with the sample enumeration on selected characteristics,

(2) what significant differences in selected characteristics existed between the respondents and non-respondents, and

(3) whether or not, any of the selected characteristics were associated with the wave of return.

Shown in Table 9 is a summary of the response after each procedural stage by the selected individual and household characteristics. Also, available enumeration values of the characteristics for either the sample or the study population are given for comparison. The underlined values shown in Table 9 are proportionally different from the enumeration by less than 10 percent*. Before making more detailed statistical comparisons, this 10 percent criterion will be used for cursory comparisons.

The total survey returns were reasonably comparable to the enumeration values on the variables of sex, city, occupational SES, and dwelling unit structure type. Sex

\footnotetext{
Percent Difference

Enumerated Percent $\times 100 \%<10 \%$
} 
IABLt. 9. Cumuletive Survey Response By Selected Characteristics

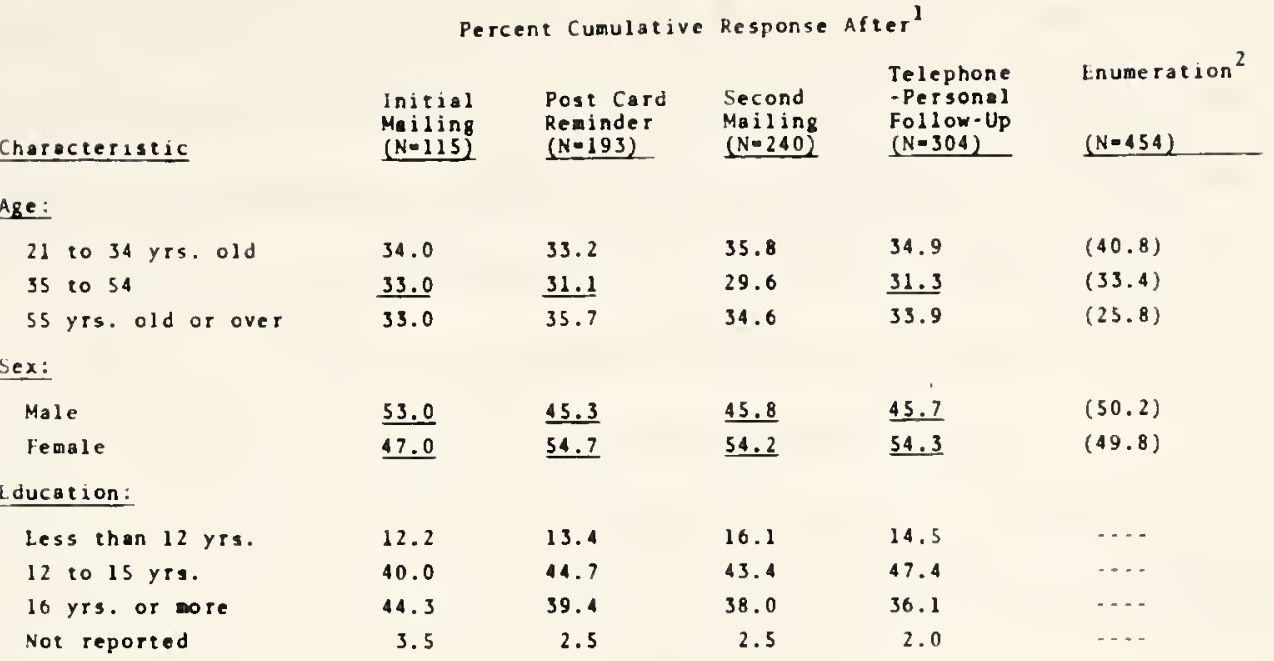

Resident Time:

10 yrs. or less

11 to 29 yrs.

30 yrs. or more

$\frac{44.4}{26.0}$

35.9

27.2

36.5

33.7

$47.1^{3}$

29.6

34.8

29.1

32.3

27.8

ciey:

\section{Lafayet te}

w. Lafayet to

$\frac{67.8}{32.2}$

71.5

34.3

34.0

25.1

occupetion (Head) :

$$
\text { High SES }
$$

Middle SES

LOW SES

Collere Student

Retijed

Unde terwined

\section{Composition:}$$
\text { Single }
$$

Martied-no chlldren

Mertied-with children

other

40.9
30.4
14.7
6.1
$\frac{7.0}{.9}$

$$
34.7
$$

33.6

15.5

6.7

6. 3

1.0

72.1

$\frac{72.0}{28.0}$

71.8

$\underline{27.9}$

28.2

\section{Number of Persone:}

\section{One}

Two

Three or nore

11.5

29.2

12.6

30.9

48.7

6.2

7.9

32.9

33.7

17.1

7.5

7.9
.8

30.7

27.8

33.9

18.7

7.8

8.2

.7

33.9

20.7

8.4

6.8

2.4

Iwelling Unit:

Owned
Rented
Undeterained
1 unlt structure
2 or nore units

$13.0 \quad 13.5$

30.4

35.2

56.5

51.3

13.9

13.9

31.1

47.9

31.5

47.0

7.6

-...

7.1

14.6

14.5

34.6

50.8

34.9

50.7

$\begin{array}{ll}66.1 & 70.5 \\ 33.9 & 29.5\end{array}$

70.0

65.8

33.9

59.7

...

....

30.0

.3

39.2

$75.7 \quad 76.2$

75.0

$\underline{72.7}$

$\underline{27.3}$

69.

30.2

I Unerl tod values

$\begin{array}{llll}24.3 & 23.8 & 25.0 & 27.3\end{array}$

10 percent

2

Velus shom in ( ) ere from the 1970 Conses of the Populetion for the study cities. All other values are from the trensportation study date.

3

Includes the resident tine of the head of the non-respanding housetolds. 
and city were the only variables within 10 percent after each stage. The bias on age and home ownership was consistent over all stages. The categorical distributions of returns on household composition and number of persons were also similar for each wave of return. The differences between early and late respondents were reflected on sex, education, resident time, and occupational SES.

For considering survey response and the selected characteristics more specifically, two statistical analyses were performed with the data. These were:

(1) a comparison of survey respondents and nonrespondents on selected characteristics, and a test of association between the wave of return and the selected characteristics.

Chi-square $\left(x^{2}\right)$ was used as the test statistic for significant differences from what would be expected from the hypothesis of equal proportionality. The level of confidence chosen for rejecting the equal proportionality hypothesis was the 0.10 probability level.

To measure the strength of any associated differences, the non-parametric statistic, Cramer's V, was used which is defined as

$$
v^{2}=\frac{x^{2}}{N \operatorname{Min}\left(\begin{array}{l}
r-1 \\
c-1
\end{array}\right)}
$$

where Min $\left(\begin{array}{c}r-1 \\ c-1\end{array}\right)$ is the minimum value of either the rows or columns munus one. This statistic takes on values ranging 
from 0 to 1 , for no association to a perfect association, while accounting for unequal rows and columns. Even though values of Cramer's $V$ between 0 and 1 don't have much intuitive meaning, the statistic does serve the purpose of a comparative indicator of the strength of different associations.

Shown in Table 10 are the survey respondents and nonrespondents by the characteristic variables enumerated for the sample. As shown, the respondent group had proportionally a larger number of long time residents, home owners, and persons living in single unit dwellings. The non-respondents were more likely to be short time residents, renting, and living in multiple unit structures. These three characteristics are probably highly correlated with each other. The groups were comparable on city location while showing slightly the typical high and low SES differences. The Cramer's $V$ measure of the strength of the association indicates comparatively that resident time in the community was the most distinguishing characteristic between the respondents and non-respondents of those considered. The resident time taken for the non-respondent households is that of the household "head". This bias, however, is not likely to cause a rival explanation of the results since it would be reasonable to assume that in most cases the resident time of the household head would be as long as, or longer than, the resident time of any of the household members who might have responded. The 
TABLE 10. Respondents and Non-Respondents By Enumerated Characteristics

Total Non- $\quad x^{2}$ Test of

Respondents Respondents Significant Cramer's

Characteristic

$\left(\mathrm{N}_{\mathrm{R}}=304\right)$

Difference $(p)$

\section{City}

Lafayette

72.0

71.3

$\mathrm{NS}^{1}$

W. Lafayette

28.0

28.7

$\underline{\text { Resident Time }}$

10 yrs. or 1 ess

33.7

$68.5^{2}$

0.0001

0.34

11 to 29 yrs.

32.3

21.5

30 yrs. or more 34.0

10.0

Occupation (Head) ${ }^{3}$

High SES

Middle SES

LOW SES

Dwelling Unit
66.0

Rented

34.0

1 unit structure 72.7

2 or more units 27.3
37.1

40.5

22.4
26.7

42.5

30.8

NS

48.6

0.001

0.17

51.4

64.0

0.07

0.09

${ }^{1}$ Not significantly different at the 0.10 level of confidence. ${ }^{2}$ Resident time of head of non-responding households. ${ }^{3}$ Respondents $=254 ;$ Non-respondents $=111$. 
mean resident time of the respondents was 23.4 years and 7.35 years for the non-respondents. Within the 10 years or less category, 74 percent of the non-respondents had been in the community for only 3 years or less, whereas only 43 percent of the respondents within this category had resident times of 3 years or less. When the data are broken down using the 3 year or less category, the association becomes more pronounced as shown in Table 11.

TABLE 11. Survey Response By Resident Time

Resident Time (years)

3 or less

4 to 29

30 or more
Respondents

13.1

53.0

$\underline{33.9}$

100.0

$(\mathrm{N}=304)$
Non $\underline{\text { Respondents }}$

50.6 $x^{2}=81.0$

39.4

$\mathrm{df}=2$

p $\quad .0001$

100.0

$(\mathrm{N}=150)$

To elaborate further on the association between survey response and resident time, the other enumerated characteristics were used as test factors, or controls, to see if the association was conditional upon any of these variables. Shown in Table 12 are the survey respondents and non-respondents by resident time controlling on occupational SES, tenure, structure type and city. As shown, the association was still statistically significant for all the subgroups and comparable in strength to the 


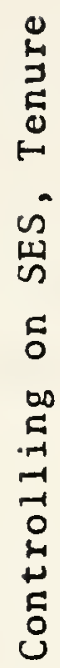

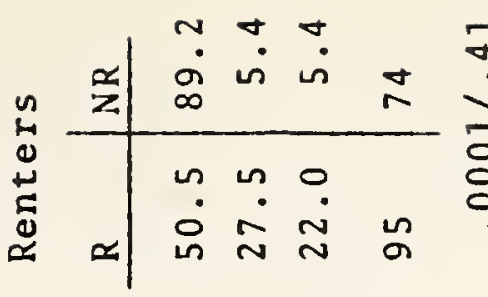

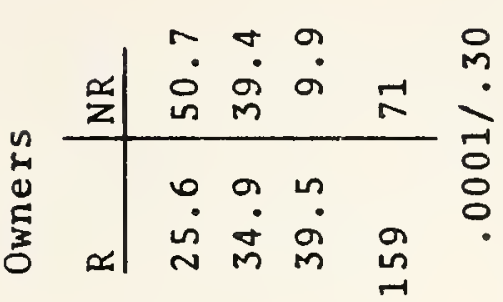

$\stackrel{\oplus}{E}$

$+\pi$

อี

$\rightarrow$

- 0

น ก

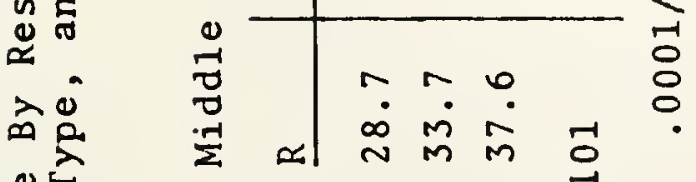

a

n!

도

모

U

$\stackrel{\sim}{\simeq} \infty$

入.ศ

$>-1$

ज豞

告
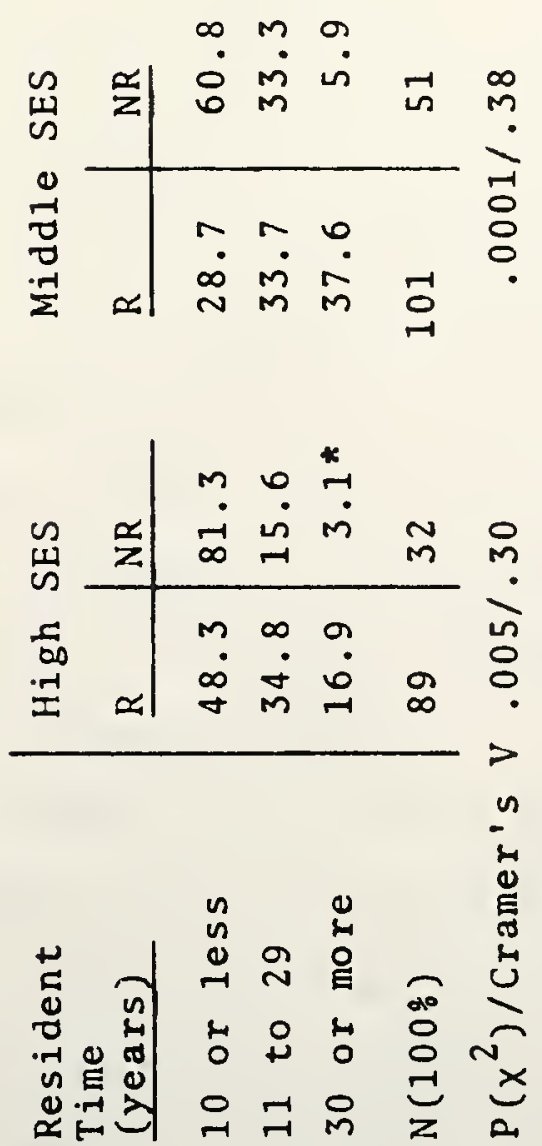

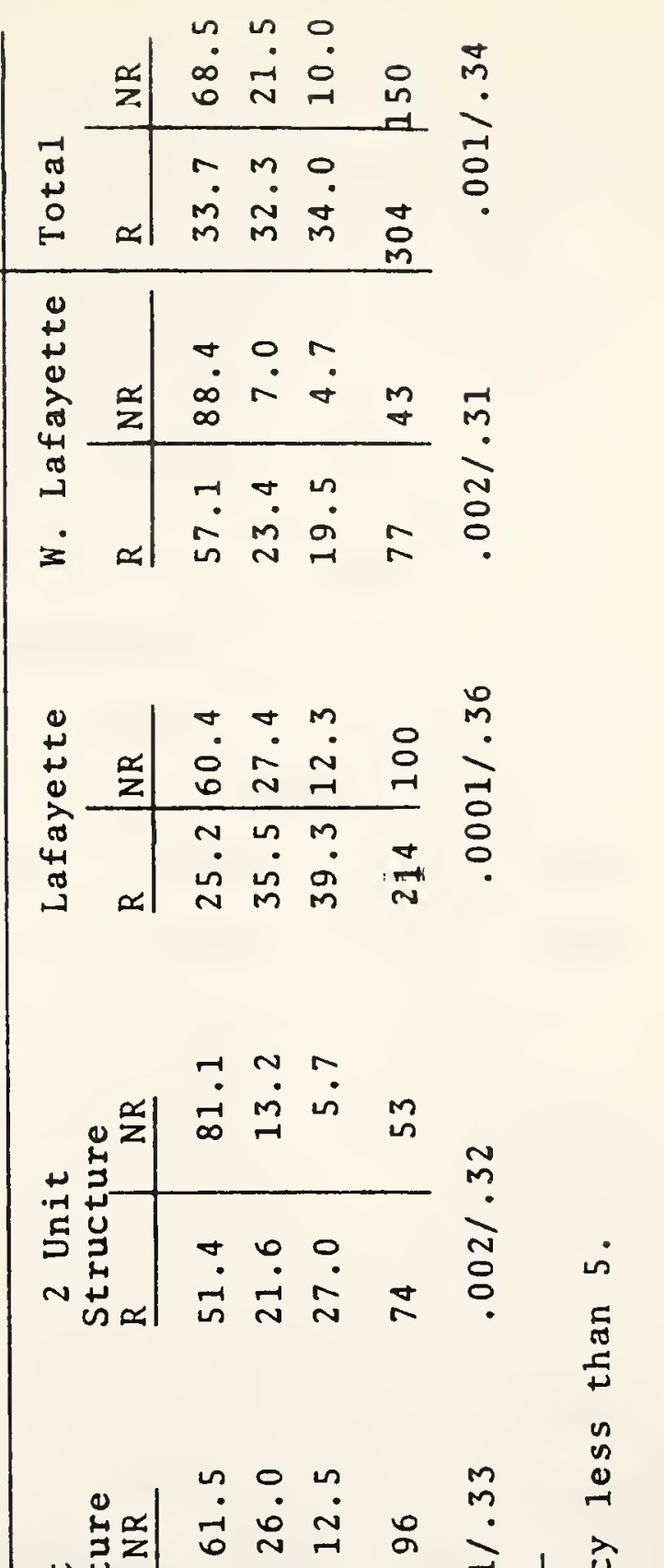

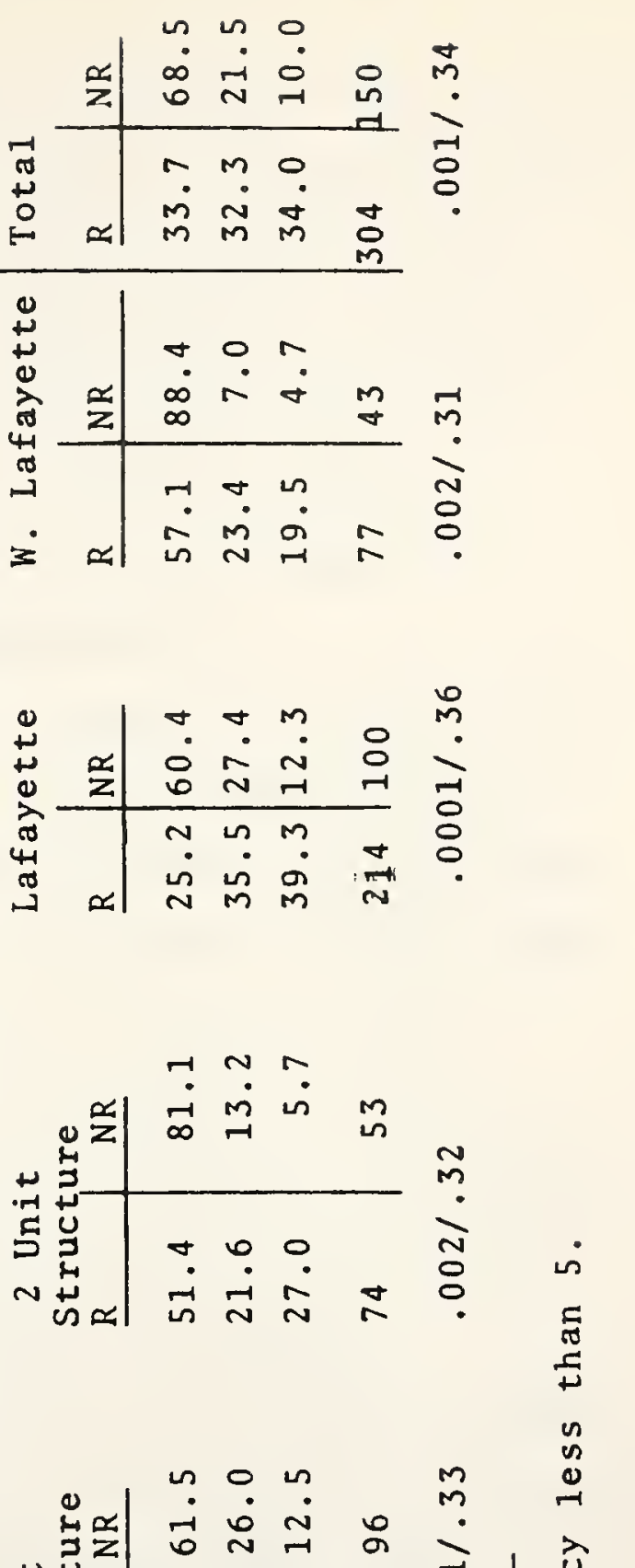

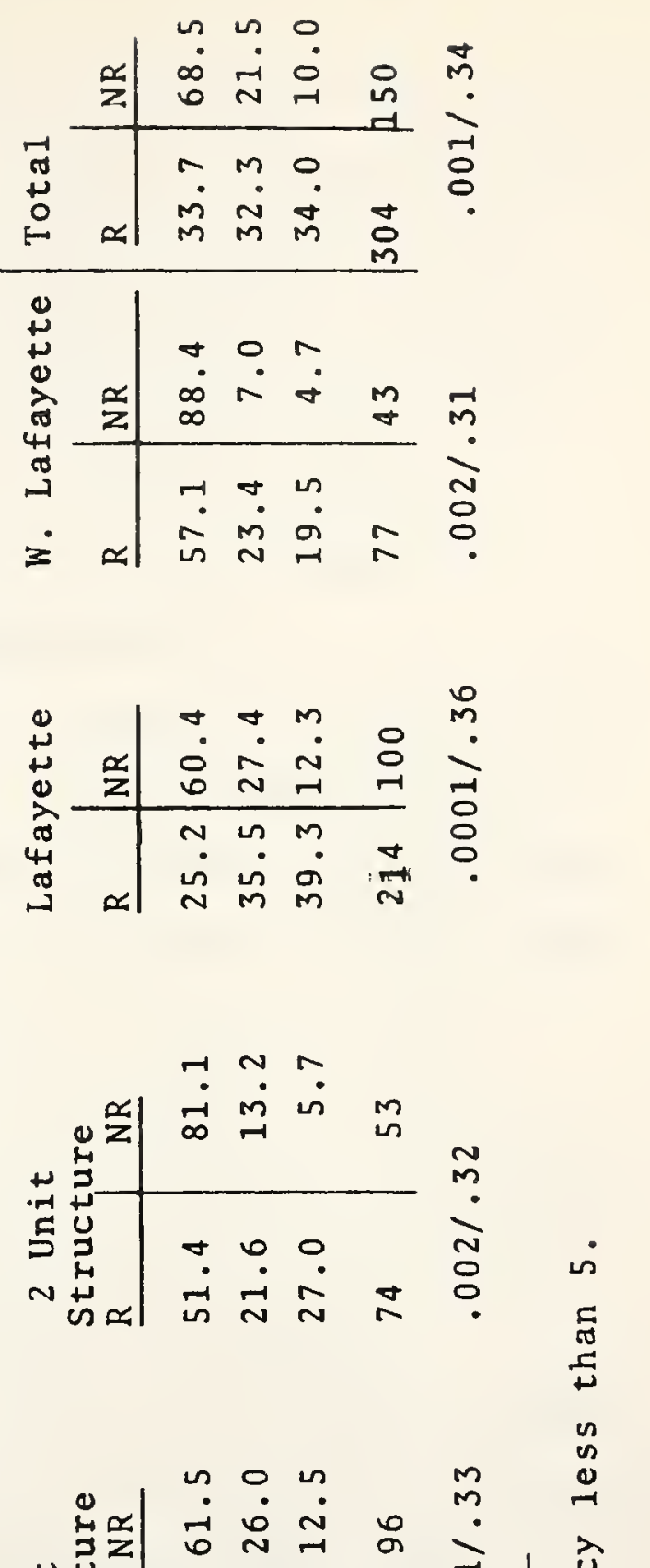

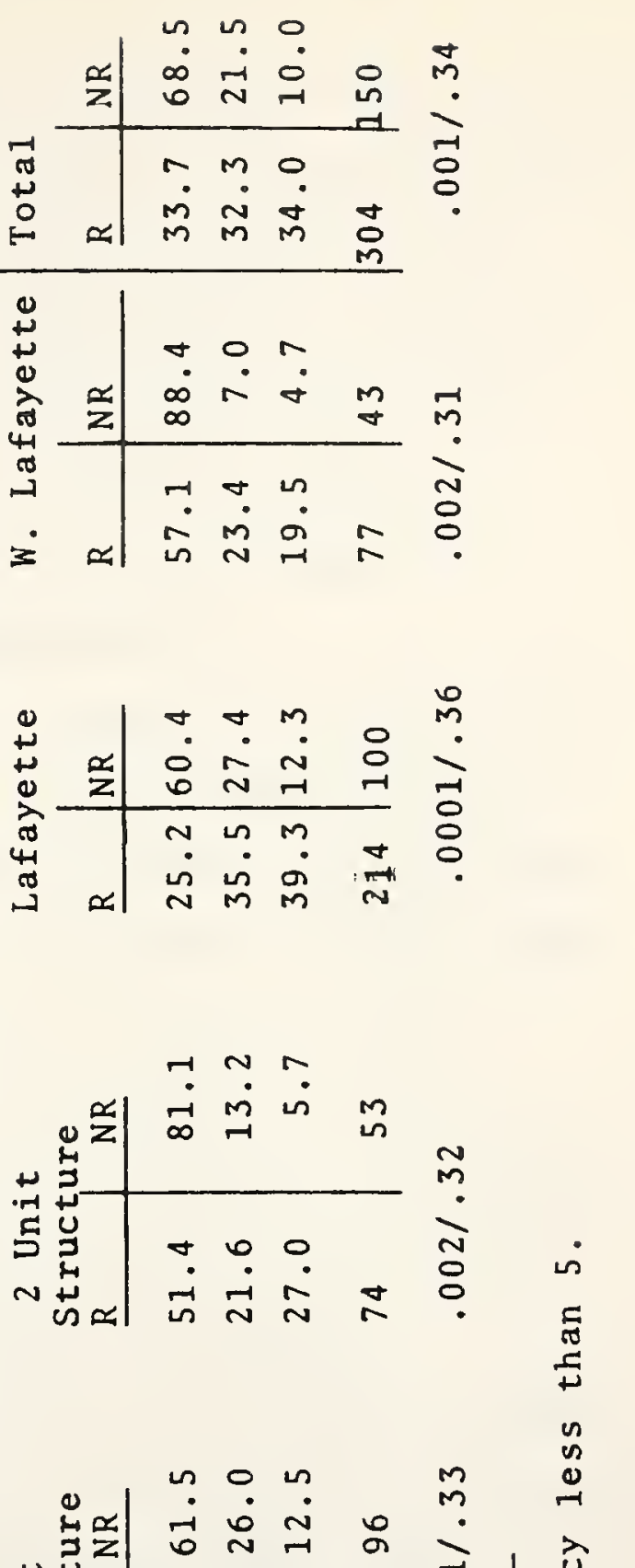

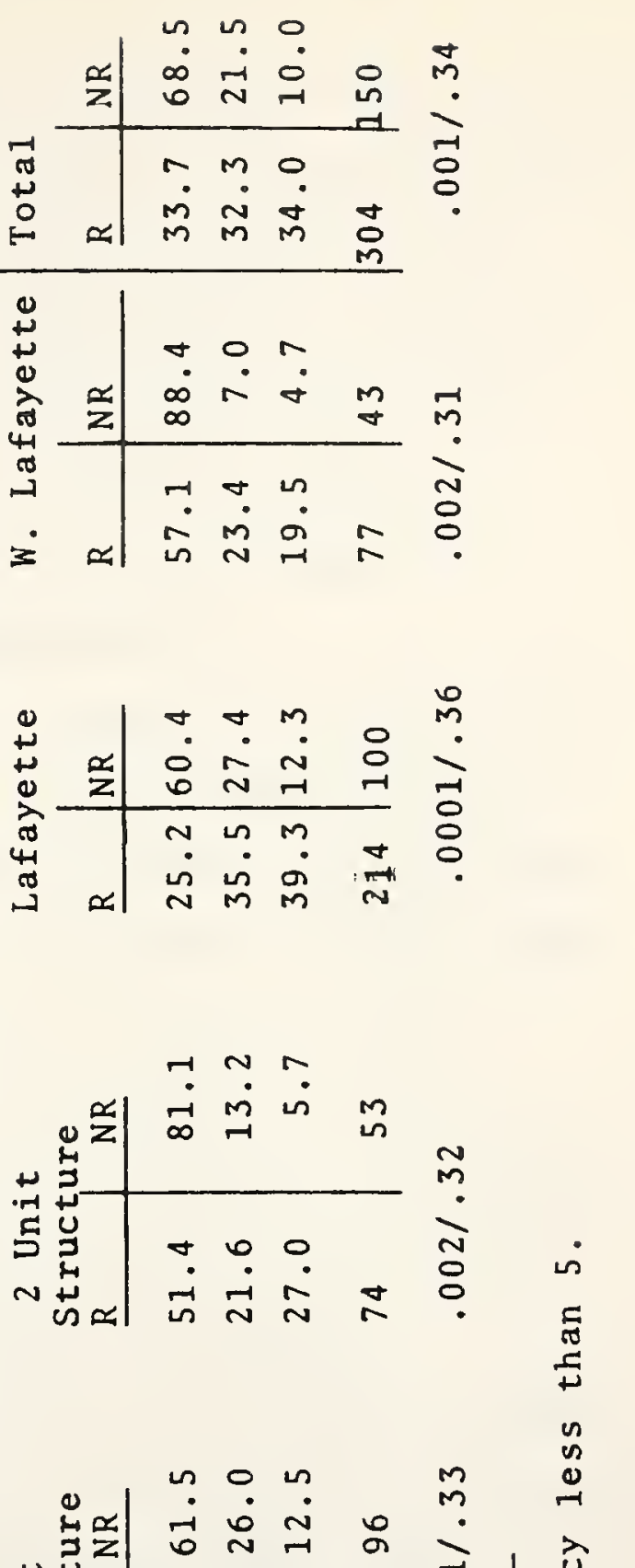

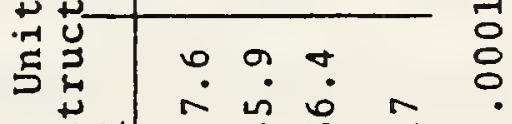

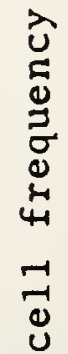

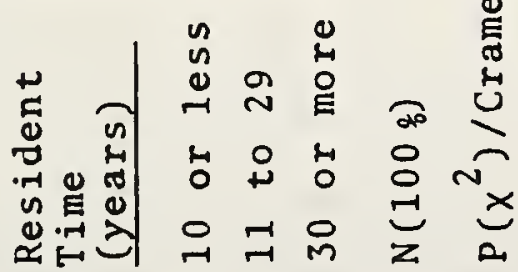

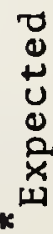


original association. These results reinforce the conclusion that the resident time in the community has a more dominant influence on the response to a mailed community related questionnaire than any of the other variables considered. Also, as shown by the relative values for Cramer's $V$ in Table 12, target populations low on SES and short on resident time will likely to be the most unresponsive group to a mailed community questionnaire.

The association of survey response with resident time is not considered surprising. It merely reinforces the common sense notion that community interest and awareness is likely to be higher amongst longer time residents than it is for the more recent arrivals. Linking longer resident time with increased community awareness and survey response would reinforce the findings of past mail survey research that the interest in the survey subject matter is the strongest determinant of response.

Referring back to Table 10 again, the survey response showed the typical high and low SES bias on the occupational measure although the difference was not found statistically significant. The initially strong SES bias was reduced by the follow-up efforts.

In Table 13 is shown a comparison of the survey respondents with the study population on age and sex. The survey returns were found to be biased on the youngest and the two oldest age categories. For the 25 to 54 year old range, however, the survey returns were proportionally 
TABLE 13. Survey Respondents and Study Population By Age and Sex $\begin{array}{lll}\text { Survey } & \text { Study } & \mathrm{X}^{2} \text { Test of } \\ \text { Respondents } & \text { Population } & \text { Significant }\end{array}$

Characteristic

$(\mathrm{N}=304)$

$(\mathrm{N}-40,567)$ Difference

Age

21 to 24 yrs. old

12.2

18.6

25 to 34

22.7

22.2

35 to 44

16.1

17.9

0.10

45 to 54

15.1

15.5

55 to 64

16.8

12.3

65 yrs. old or over

17.1

13.5

$\underline{\operatorname{Sex}}$

Male

45.7

49.9

NS

Female

54.3

50.1

* 1970 Census of the Population. 
representative of the population. The female bias in the sample returns was not statistically significant.

Shown in Table 14 is the complete breakdown by wave of return for those characteristics on which some association with the wave of return was found to be statistically significant. No associations were found within the 0.10 probability level on the characteristics of age, city, household composition and number of persons, or dwelling unit structure type.

As can be seen in Table 14, the initial respondents were proportionally higher in the male, higher educated and occupational groups, and shorter time residents than those of the later stages. The response to the telephone and personal follow-ups had a greater percentage of female,middle educated, middle and lower occupations, longer time residents, and renters.

Although the characteristics shown in Table 14 were found to have statistically significant associations with the wave of return, all the associations were comparatively weak as reflected by the values for Cramer's $V$. The practical significance of these results is only that the bias in mail returns is more likely to be on these characteristics than the others considered, and the use of the non-mail follow-ups helped reduce these biases. For example, the respondents to the non-mail follow-ups were significantly different* from the respondents to the mail-

${ }^{*} x^{2}$ probability less than 0.10. 
TABLE 14. Wave of Return By Selected Characteristics

\begin{tabular}{|c|c|c|c|c|c|c|c|}
\hline Characteristic & $\begin{array}{c}\text { Wave } 0 \\
\underline{1}\end{array}$ & $\begin{array}{l}\operatorname{Re} t \mathrm{t} \\
2\end{array}$ & $\operatorname{urn}_{3}(\mathrm{Pe}$ & (rcent) & $\underline{N}$ & $\begin{array}{l}x^{2} \\
(p) \\
\end{array}$ & $\begin{array}{c}\text { Cramer's } \\
\mathrm{V}\end{array}$ \\
\hline$\underline{\text { Sex }}$ & & & & & 304 & .06 & .16 \\
\hline Male & 53.0 & 33.0 & 48.9 & 45.3 & & & \\
\hline \multirow[t]{2}{*}{ Female } & $\underline{47.0}$ & $\underline{66.7}$ & $\underline{51.1}$ & $\underline{54.7}$ & & & \\
\hline & $\begin{array}{r}100.0 \\
(115)\end{array}$ & $\begin{array}{r}100.0 \\
(71)\end{array}$ & $\begin{array}{r}100.0 \\
(47)\end{array}$ & $\begin{array}{r}100.0 \\
(64)\end{array}$ & & & \\
\hline \multicolumn{5}{|l|}{ Education } & 298 & .01 & .17 \\
\hline \multirow{4}{*}{$\begin{array}{l}<12 \text { yrs. } \\
12 \text { to } 15 \text { yrs } \\
\geq 16 \text { yrs. }\end{array}$} & 12.6 & 15.4 & 27.7 & 8.1 & & & \\
\hline & 41.4 & 52.6 & 38.3 & 62.9 & & & \\
\hline & 45.9 & 32.1 & 34.0 & 29.0 & & & \\
\hline & $(111)$ & $(78)$ & $(47)$ & $(62)$ & & & \\
\hline \multicolumn{5}{|c|}{ Occupation (Head) } & 254 & .10 & .14 \\
\hline High SES & 48.0 & 30.6 & 30.8 & 28.3 & & & \\
\hline Middle SES & 35.0 & 48.4 & 41.0 & 41.5 & & & \\
\hline \multirow[t]{2}{*}{ Low SES } & 17.0 & 21.0 & 28.2 & 30.2 & & & \\
\hline & $(100)$ & $(62)$ & (39) & (53) & & & \\
\hline \multicolumn{2}{|l|}{ Resident Time } & & & & 304 & .10 & .14 \\
\hline$\leq 10 \mathrm{yrs}$. & 44.4 & 35.9 & 36.5 & 33.7 & & & \\
\hline 11 to 29 & 26.0 & 27.2 & 29.1 & 32.3 & & & \\
\hline \multirow[t]{2}{*}{$\geq 30 \mathrm{yrs}$} & 29.6 & 34.8 & 34.3 & 34.0 & & & \\
\hline & $(115)$ & $(78)$ & $(47)$ & $(64)$ & & & \\
\hline \multicolumn{2}{|l|}{ Dwelling Unit } & & & & 303 & .02 & .19 \\
\hline \multirow{3}{*}{$\begin{array}{l}\text { Owned } \\
\text { Rented }\end{array}$} & 66.1 & 76.9 & 68.1 & 50.8 & & & \\
\hline & 33.9 & 23.1 & 31.9 & 49.2 & & & \\
\hline & $(115)$ & $(78)$ & $(47)$ & (63) & & & \\
\hline
\end{tabular}


out portion on education, resident time, occupational SES, and home ownership.

In summary, the sample returns were found to be underrepresentative of the younger age group (21 to 24 years old), males, short time residents, renters, and persons living in multiple dwelling unit structures. Whereas, the returns were overrepresentative of the older age group ( 55 years old or over), females, long time residents, home owners, and persons living in single family dwelling units. The differences between respondents and non-respondents on city and occupational SES were less than those given above. The most significant difference found was on resident time with shorter time residents showing the greatest degree of non-response of any group considered.

Technically speaking, the bias found in the sample returns on some of the socio-demographic characteristics could be crucial for surveys having an explanatory or analytic purpose of inferring behavioral variables from attitude data. Planning surveys seeking attitude or opinion data about what residents perceive to be the major sources of dissatisfaction within a community subject area has more of an informative than an explanatory purpose. Primary to the consideration of using the mail survey approach for this informative purpose is assessing how much information is lost due to the non-response and to what degree is the information obtained peculiar to the 
characteristic nature of the respondents. From the opinion data collected in this study, one cannot determine if, or how strong, a relationship might exist between a groups reactions to their community environment and their sociodemographic characteristics. The data gathered, however, is considered of sufficient scope and detail to make some assessment on how crucial the non-response bias is to the informative purpose.

\section{Survey Data}

As given previously, the questionnaire schedule was designed to obtain resident's answers to three basic questions at the community level. These questions were:

(1) in which major categories did they seem to think the community needed the most improvement,

(2) what specific facilities, services, or conditions would they like to see improved, and

(3) how did they feel about the relative importance of several community projects which were under current consideration.

The primary interest in discussing the survey responses to the above questions is to illustrate that mailed questionnaires can collect subjective data which is informative and still useful in spite of the non-response bias. 
Questions (4), (5), and (6) (see page 107) of the questionnaire schedule were directed at obtaining some answer to the above questions. Only the survey responses to these questions will be presented and discussed in the text. The survey responses to what features of the Greater Lafayette area the residents liked the most and what kind of improvements they thought should be made in their neighborhoods are summarily given in Appendix D.

\section{Major Category Improvement}

Respondent's opinions about which major categories of community concern are in the most need of improvement were interpreted as indicators or measures of their dissatisfaction with these areas of the community environment. This interpretation is made with the understanding that the relative dissatisfaction with major categories will be partly dependent on the degree of contact or awareness the respondent has had with the universe of objects or activities within these major categories.

As stated in the study design, the respondent's answers to the general checklist question (4) or their specific suggestions for improvements, question (5), could both reflect their relative dissatisfaction with major community categories. The answers for question (4) could be directly coded. For question (5a), the specific suggestions had to be edited and coded by major category. The details of the coding procedure and the judgements made 
for (5a) are presented in Appendix D. It will suffice here to point out that 87.6 percent of the 730 specific responses to ( $5 a$ ) were coded in the same major category as given by the respondent. Furthermore, consistency checks of every respondent's answers to both questions (4) and (5a) weremade. It was found that 3 out of every 4 (74 percent) of the specific suggestions for improvements given by the respondents to question ( 5 a) were in categories which were a1so checked in question (4).

Shown in Figure 1, for comparison, is the response distributions to questions (4) and (5a) by major category with the categories listed in decreasing order of their frequency of response to question (4). The consistency between the responses to the two questions was quite high which reinforces not treating them methodologically as independent measures. The facilities, services, and conditions associated with the community transportation system was overwhelmingly the major source of dissatisfaction. On the other end of the scale, education, health care, public utilities and assistance were considered to need the least improvement.

Figure 1 basically shows what major categories the respondents thought were in the most need of improvement. To qualify any inference of these answers to the nonrespondents or to the total population, the cumulative frequency distribution to question (4) was computed after each wave of return to check consistency. In Table 15, the 


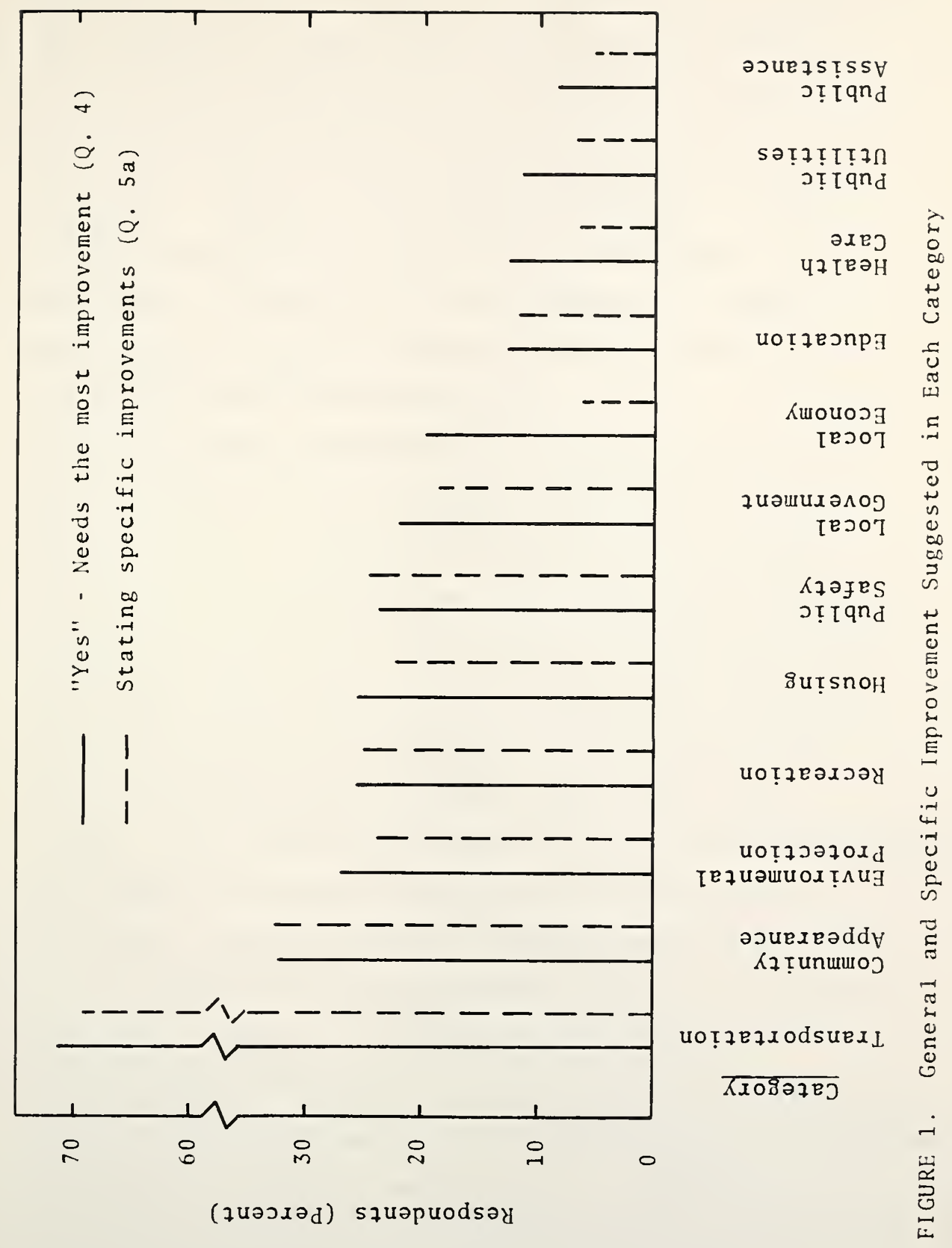


cumulative frequency percent for question (4) is shown with the categories listed by their final rank order frequency. As can be seen, the relative positions of the top four and the bottom five categories did not change after each wave of return. The other three categories did vary in their relative positions. From the consistency shown, there is some basis for expecting the non-respondent's answers to this question to not be significantly different from what was obtained from the respondents.

The response distribution to question (4) was broken down by characteristic subgroups. The distributions are shown in Table 16. The distributions for the student, retired, and the miscellaneous family composition subgroups are not presented since these groups had less than 20 cases and could result in misleading representation. The groups shown, of course, are not mutually exclusive, and a high degree of overlap exists between some of them. For example, oldnr people are likely to be also long time residents, home owners are likely to be dwelling in single unit structures, highly educated in high SES occupations, etc. An attempt to completely discuss Table 16 will not be made here. However, the general similarities and dissimilarities reflected by the data are of interest. Similarities can be seen in the overall rank order frequencies of the major categories amongst all the subgroups. Differences in the level of dissatisfaction or concern with a given category amongst the subgroups on a given characteristic are also noticeable. 
TABLE 15. Categories Needing the Most Improvement By Wave of Return

\begin{tabular}{|c|c|c|c|c|}
\hline $\begin{array}{l}\text { Major } \\
\text { Category } \\
\end{array}$ & $\begin{array}{l}\text { First } \\
\text { Wave } \\
(\mathrm{N}=108) \\
\end{array}$ & $\begin{array}{l}\text { Second } \\
\text { Wave } \\
(\mathrm{N}=178) \\
\end{array}$ & $\begin{array}{l}\text { Third } \\
\text { Wave } \\
(\mathrm{N}=223)\end{array}$ & $\begin{array}{l}\text { Fourth } \\
\text { Wave } \\
(\mathrm{N}=283)\end{array}$ \\
\hline $\begin{array}{l}\text { Transpor- } \\
\text { tation }\end{array}$ & 68.5 & 65.7 & 66.9 & 68.7 \\
\hline $\begin{array}{l}\text { Community } \\
\text { Appearance }\end{array}$ & 28.7 & 32.0 & 31.4 & 31.1 \\
\hline $\begin{array}{l}\text { Environ- } \\
\text { menta1 } \\
\text { Protection }\end{array}$ & 29.6 & 28.6 & 28.6 & 25.7 \\
\hline Recreation & 27.8 & 24.7 & 24.1 & 24.9 \\
\hline Hous ing & 20.4 & 20.2 & 22.0 & 24.6 \\
\hline $\begin{array}{l}\text { Pub1ic } \\
\text { Safety }\end{array}$ & 19.4 & 21.8 & 22.5 & 22.9 \\
\hline $\begin{array}{l}\text { Local } \\
\text { Government }\end{array}$ & 23.1 & 23.5 & 23.6 & 21.1 \\
\hline $\begin{array}{l}\text { Local } \\
\text { Economy }\end{array}$ & 16.7 & 20.2 & 18.8 & 19.0 \\
\hline $\begin{array}{l}\text { Health } \\
\text { Care }\end{array}$ & 11.1 & 12.4 & 12.1 & 12.3 \\
\hline Education & 10.1 & 10.7 & 12.0 & 11.3 \\
\hline $\begin{array}{l}\text { Public } \\
\text { Utilities }\end{array}$ & 9.3 & 9.0 & 9.8 & 10.9 \\
\hline $\begin{array}{l}\text { Public } \\
\text { Assistance }\end{array}$ & 8.3 & 7.2 & 7.5 & 7.7 \\
\hline
\end{tabular}


TABLE 16. Categories Vecding the Most Improvement by Characteristic Subgroups

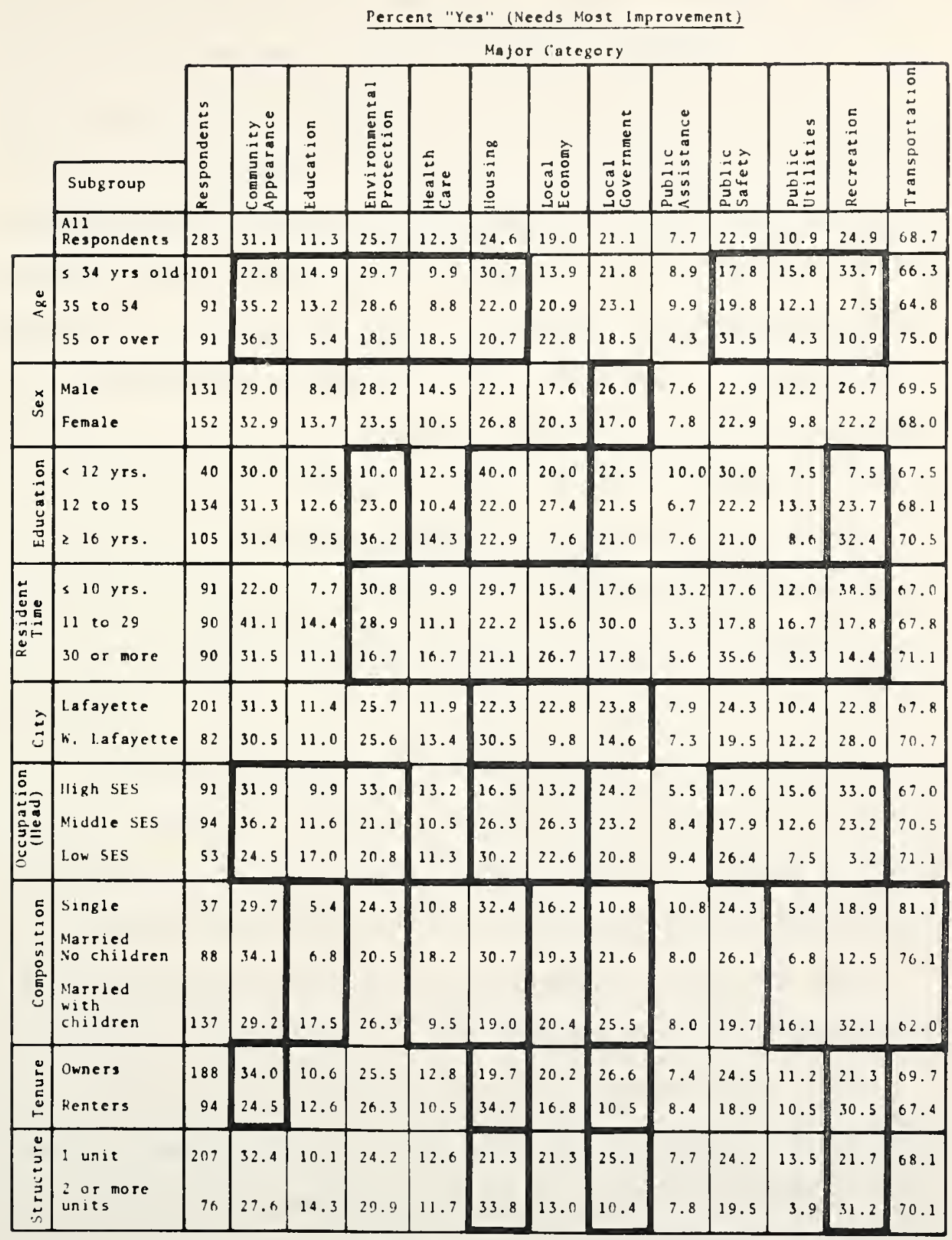


With respect to the similarities, the transportation category maintained its dominance as the greatest source of dissatisfaction over all the groups. In most cases, the appearance of the community was the second or third greatest source of concern. The categories of transportation, community appearance, environmental protection, recreation, housing, public safety, and local government most frequently appeared as one of the top six categories as needing the most improvement. Whereas, the categories of education, health care, public utilities, and public assistance were not found in the top six for any of the subgroups, The consistency of this dichotomy over the characteristic subgroups indicates that some of these categories were generally of more primary concern to most subgroups in the community.

Noticeable differences, of course, can be found amongst specific subgroup dissatisfactions with particular categories. Some of these differences are marked in Table 16 by heavy lined boxes. The differences were highlighted on inspection for being of some interest with no real criterion being applied. The characteristic subgroups on age, education, resident time, occupational SES, and family composition had more noticeable opinion differences for more of the categories than those found between subgroups on sex, city, tenure, or type of dwelling unit structure. 
The age and resident time subgroups are closely associated with one another. The older and longer time residents indicated greater dissatisfaction than younger, shorter time residents with the appearance of the community, health care, the local economy, and public safety. Whereas, the younger and shorter time residents reflected a greater concern about protecting the environment and with housing, utilities, and recreation. The differences delineated on these age linked subgroups reflect some of the distinct preferences and desires associated with different stages of the life cycle.

The subgroups defined by occupation and education are also closely associated since these two characteristics are component measures of SES. As shown, the corresponding subgroups on both these characteristics exhibited similar differences in their dissatisfaction with the present situation for protecting the environment, in the housing and economic conditions, and with the recreational facilities. The higher SES groups indicated greater concern about environmental protection and recreation, whereas, the low SES group was more dissatisfied with the conditions in housing, the economy, and for public safety. The low SES group was also somewhat more concerned about education.

The various needs which are associated with family status were also reflected in the data. Married people with children showed greater interest in improving the facilities 
and services in education and recreation than those without children. Respondents with children were also more concerned with improving the local government and public utility operations. On the other hand, single people were more dissatisfied with the community's ability to provide for their primary needs in housing and transportation. Married people without children showed a contrasting degree of dissatisfaction with health care. The level of their dissatisfaction was one of the two highest of all the subgroups on health care.

Also shown in Table 16 marked by underlines are those subgroups having the most dissatisfaction within each given category.

Generally speaking, both the similarities and dissimilarities displayed in Table 16 are informative. The consistency of all the subgroups to point out basically the same six or seven categories as major sources of dissatisfaction indicates that improvements within these major categories might have a higher utility value to the general public. On the other hand, the dissimilarties found reflect the variation of interests expected amongst different subgroups of the population. Differences in opinion were found more frequently among the subgroups defined by the age-linked, SES, and family status characteristics. Planning projects or programs seeking public input might bemore likely to discover if there is a wide difference of interest or favor for a given facility 
or service by focusing on the opinions of these subgroups rather than the others considered.

Specific Improvements Suggested

As was discussed in the study design, the format of qeustion ( $5 a$ ) was chosen to allow respondents to point out what specific facilities, services, or conditions they wanted to see improved. On answering this question, respondents would generally indicate with which aspect of a given facility, service, or condition they were dissatisfied if it was not apparent. A wide range of responses were obtained due to the universe covered by the twelve major categories. A sample of some of the verbatim responses to question ( $5 a$ ) are given in Appendix $D$ to exemplify the kind of responses obtained.

The responses were edited and coded by major and minor categories. A certain degree of judgement is always involved in coding such free responses. In some cases, the response could logically fall under two major categories with the choice of either one being mostly academic. The minor categories representing the most frequently suggested improvements within each major category are given in Appendix $D$ to depict the classification scheme used. Shown in Table 17 is a list of the major facilities, services, and conditions with which at least ten respondents indicated some improvement to be necessary. When the universe of possible responses is considered, ten respondents 
TABLE 17. Specific Improvements Most Frequently Suggested

I would like to see:

a. the bus service improved

b. restoration of buildings in downtown area

c. the polluting buses eliminated

d. the downtown railroad crossings eliminated

e. stricter air pollution controls

f. traffic signals - more installations more overhead signs

g. lower taxes and better use of tax money

h. more lower cost housing for retired and low income groups

i. better enforcement of traffic laws and speed 1 imits

j. bicycle lanes

$k$. the Wabash River cleaned up

1. the streets and alleys cleaned up

$m$. more neighborhood parks for children

n. lower rent and housing costs

o. a change in city and county office holders

p. Columbian Park improved

q. housing codes improved and enforced

$r$ a combination of Lafayette and West Lafayette city governments

s. a government more responsive to the interests of the people

$t$. more vocational training opportunities

u. the riverfront park developed

$v$. more recreational facilities for young and old adults

w. the telephone service improved $\underline{\text { Responses }}$

82

29

28

23

23

22

21

17

17

14

14

13

13

12

11

11

10

10

10

10

10

10

10 
pointing out the same improvement is a relatively significant indication. The 1 ist contains those improvements of most specific concern to the respondents and is not necessarily an indication of the relative priority they would assign to improving these facilities, services, or conditions.

Improving the local bus system was a salient public issue at the time this survey was conducted. The relatively large number of respondents suggesting something to be done about the bus service was, no doubt, partly due to this wide publicity. The raw comments indicated that the major dissatisfactions with the present bus system were the routes being covered, the scheduling was inconvenient for transfers downtown, the attitudes of the bus drivers, and the pollution from the old buses.

Most of the respondents who suggested restoration of the buildings in the downtown area made some reference to the work which had recently been done on the courthouse. Seemingly, the sand blast cleaning of the courthouse had stimulated some interest in doing the same to the other buildings in the downtown area.

The raw comments of those wanting to see bicycle lanes established in the present street system indicated that both bicycle riders and automobile drivers were making the suggestions. The users of both modes pointed out that their primary concern in suggesting bicycle lanes was with traffic safety. 
The comments about Columbian Park were directed at cleaning up the zoo and eliminating the commercialized rides.

The suggestions for housing code improvement were directed at adopting stricter codes with more uniform application.

The other improvements given in the list are basically self-explanatory.

Considering that over 730 specific responses were obtained to question ( 5 a) from 235 residents of the community, it is not likely that the non-respondents would have pointed out any additional major sources of dissatisfaction.

The data for question (5b) was not compiled. The hasty addition of this question without a pre-test resulted in an oversight. Respondents were asked to give the suggestion number of the one improvement they wanted to see done first of those they had suggested. This resulted in many respondents giving the category number of the improvement rather than the suggestion number. When the category number of the suggested improvement corresponded with one of the four suggestion numbers, there was no way to ascertain, for sure, which suggestion the respondent indicated from the format of the question. The use of letters rather than numbers for the suggestion spaces would have prevented this problem. 
Importance of Specific Projects

With the help of a local planning official, ten community related projects were selected for presentation to the respondents. Respondents were asked to indicate the relative importance of each project by answering on a fourpoint attitude scale ranging from very important to not important at all or that they didn't really know. The specific projects and the answering format are shown in question (6) of the questionnaire.

Table 18 shows the response distributions for each project and their computed mean importance scores. The mean importance scores reflect how the projects fell into three range groups on importance. Improving the bus service, relocating the downtown railroads, and establishing an area-wide vocational high school were in the highest importance group. Building the Wildcat Reservoir got the lowest importance score while the remaining projects formed a group which was middle range in importance.

Shown in Figure 2 is a graph of the mean importance scores cumulatively computed after each wave of return. These computations were made to see if any large variations in the data occurred in the latter waves of return to assess the possibility of a serious non-response bias from the trends found. As shown by Figure 2, only small variations in the trends were found. The relative grouping and importance range of the projects were basically unchanged. On the basis of this consistency, the conclusion is again 
drawn that the general answer to this question would not likely be different if the whole sample had responded. 
U

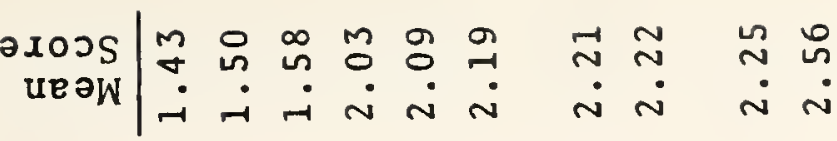

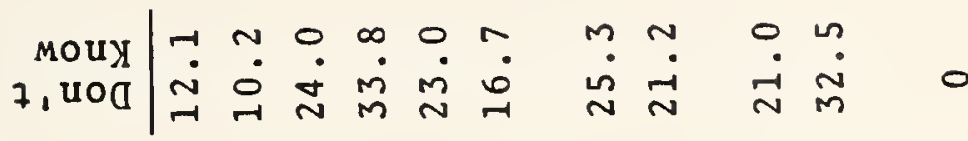

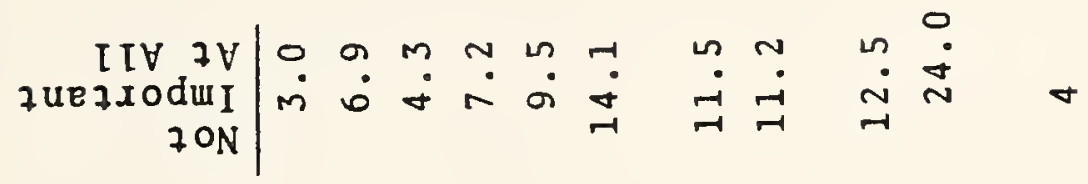

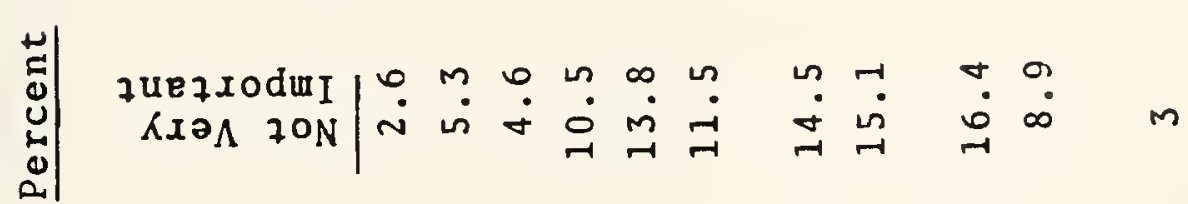

崩

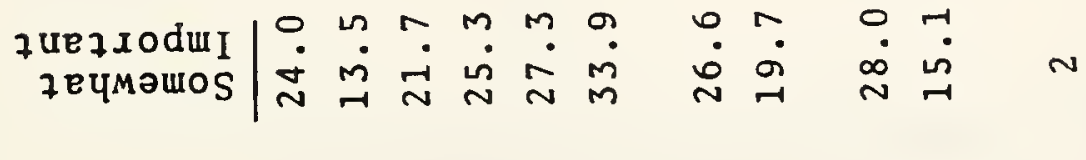

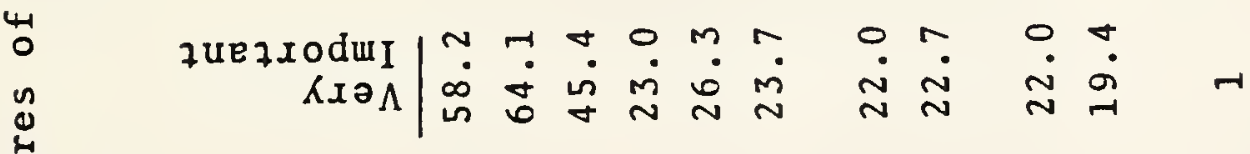

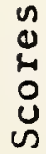

U⿱

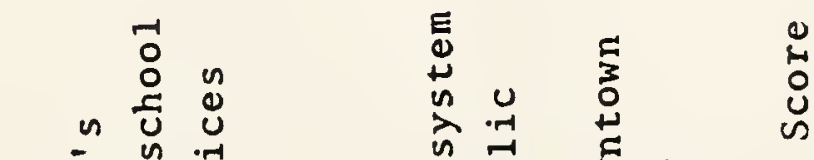

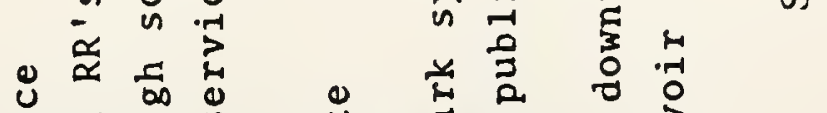

$\underset{\substack{\text { g } \\ \text { in }}}{ }$

II

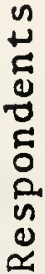

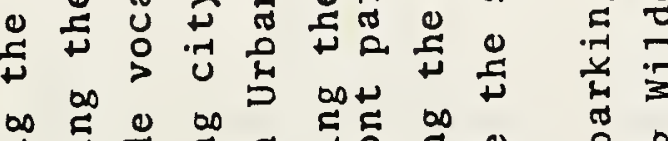

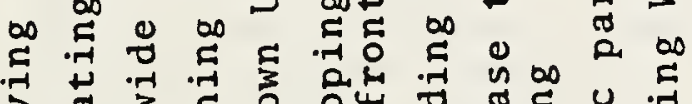

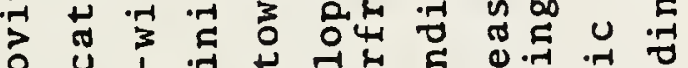

० 0 1 1 .

茨

㸃 品

先

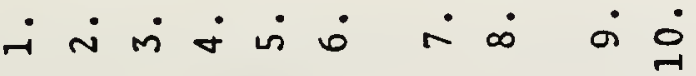




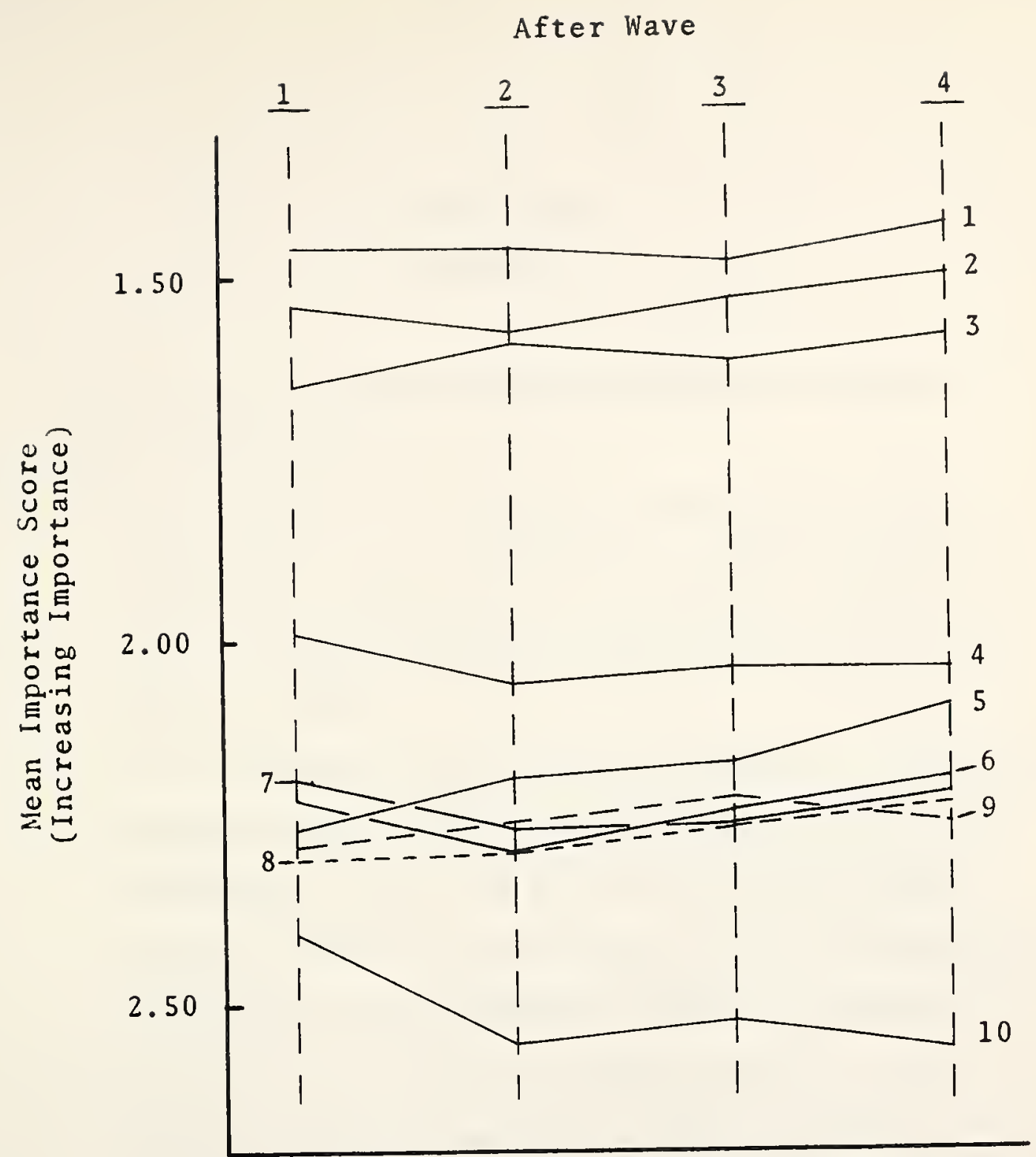

1. Improving the bus service

2. Relocating the downtown railroads

3. Area-wide vocational high school

4. Combining City-County services

5. Downtown Urban Renewal

6. Developing the Lafayette riverfront park

7. Expanding the County park system

8. Increase the supply of public housing

9. Public parking garages downtown

10. Building Wildcat Reservoir

FIGURE 2. Cumulative Mean Importance Scores of Specific Projects After Each Wave of Return 


\section{CHAPTER VII}

\section{CONCLUSIONS}

The conclusions which are drawn from the results of this study are stated below.

1. The combined use of mailed questionnaires with follow-up procedures is an economical approach for obtaining subjective opinion data from the general public.

2. For planning surveys seeking resident's subjective opinions about their community environments for informative uses, the bias due to non-response may not result in any serious loss of information if greater than 60 percent return is achieved.

3. A mailed out community related survey is not likely to achieve much more than 50 percent response unless non-mail follow-up procedures are used.

4. The combined successive use of a telephone and simplified personal follow-up to a mailed community survey is likely to be comparable to an interview follow-up on the basis of the cost versus the information obtained. 
5. Respondents to a community related mail survey are more likely to be older, longer time residents owning a single unit dwelling than are non-respondents .

6. The use of non-mail follow-up procedures in a mail survey can reduce the typical SES bias found in the response to mail surveys.

7. The response to a community related mail survey is 1 ikely to be more strongly associated with the respondent's resident time than it is with his age, sex, SES, family status or size, tenure, or type of dwelling unit.

8. Some opinion consensus is likely to exist within a community population on the major sources of dissatisfaction within the community environment independent of the population's socio-demographic make - up .

9. The relative degree of dissatisfaction or concern within given categories of the community environment is more likely to vary more between different age-linked, SES, and family status groups than it is between groups who differ on sex, tenure, or type of dwelling unit. 
B I BL I OGRAPHY 


\section{BIBLIOGRAPHY}

1. Wilson, Robert L., "Livability of the City: Attitudes and Urban Development", Urban Growth Dynamics, edited by Chapin, F. Stuart, Jr. and Weiss, Shirley F., New York, Wiley, 1962.

2. Peterson, G. L. and Worrall, R. D., "An Analysis of Individual Preferences for Accessibility to Selected Neighborhood Services", Highway Research Record, No. 305,1970 .

3. Aguar, Charles E., "The Use of Surveys in Planning", Journal of the American Society of Planning Officials, p. 106,1965 .

4. Lamanna, Richard A., "Value Consensus Among Urban Residents", Journal of The American Institute of Planners, Vo1. 30, No. 4, pp. 317-323, November 1964 .

5. Denver Planning office, "Community Directions for the City and County of Denver: A Resume of Opinions of Certain Denver Citizens on Subjects Relating to Denver Community Objectives", Comprehensive Planning Bulletin No. 1-2, October, 1964 .

6. Gans, Herbert J., People and Plans, Basic Books, Inc., New York, pp. 1-11, 1968.

7. Saroff, Jerome R. and Levitan, Alberta Z., Survey Manual for Comprehensive Urban Planning, Development Research Associates, Inc., Anchorage, Alaska, 1969.

8. Wallace, David, "A Case For-and-Against Mail Questionnaires", Public Opinion Quarterly, Vol. 18, pp. 40-52, 1954 .

9. Miller, Delbert C., Handbook of Research Design and Social Measurement, Second Edition, David McKay, Inc., New York, pp. 76-77, 1970 .

10. Barnes, Charles F., "Living Patterns and Attitude Surveys", Highway Research Record, No. 187, pp.43-54, 1967 . 
11. Hochstim, Joseph R., "A Critical Comparison of Three Strategies of Collecting Data from Households", Journal of the American Statistical Association, Vo1.62, pp. 976-989, 1967.

12. U. S. Bureau of the Census, Census Use Study: Area Travel Survey Report No. 11, U. S. Government Printing office, Washington, D. C., 1970 .

13. Clausen, John A. and Ford, Robert N., "Controlling Bias in Mail Questionnaires", Journal of the American Statistical Association, Vo1. 42, pp. 49\%-511, 1961.

14. Hochstim, Joseph R., and Athanasopoulos, Demetrios A., "Personal Follow-up in a Mail Survey: Its Contribution and Its Cost", Public Opinion Quarterly, Vol. 34 , pp. $69-81,1970$.

15. Sear, Alan M. and Champion, Dean J., "Questionnaire Response Rate: A Methodological Analysis", Social Forces, Vo1. 47, 1968.

16. Oppenheim, A. N., Questionnaire Design and Attitude Measurement, Basic Books, New York, p. 81, 1966.

17. Scott, Christopher, "Research in Mail Surveys", Royal Statistical Society, Journal A, Vo1. 124, Part 2, pp. 143-195.

18. Franzen, R. B., and Lazarfield, Paul F., "Mail Wuestionnaires as a Research Problem", Journal of Psychology, Vo1. 20, pp. 293-320, 1945.

19. Donald, Majorie N., "Implications of Non-Response for the Interpretation of Mail Questionnaire Data", Public Opinion Quarterly, Vol. 24, No. 1, p. 99, 1960 .

20. Boek, Walter and Lade, James, "A Test of the Usefulness of the Post Card Technique in a mail Questio-naire Study", Public Opinion Quarterly, Vol. 27, No. 1, p. 303, 1963.

21. Graduate Research Center of the Southwest, Goals for Dallas, Dallas, Texas, (Southern Methodist University,) 1966 .

22. Community Goals Committee, Tucson Community Goals, Tucson, Arizona, Office of City Manager, May 1966.

23. Louisville Metropolitan Comprehensive Transportation and Development Program, Community Goals and Objectives, Intermediate Report for Project No. 3.20, April, 1967. 
24. Bolles, John S. and Associates, Northern Waterfront Plan, San Francisco, California, 1968.

25. Richards, Robert, Subjective Social Indicators, National Opinion Research Center, Chicago, Illinois, 1968 .

26. Nichols, R. C. and Meyer, M. A., "Timing Post Card Follow-Ups in Mail Questionnaire Surveys", Public Opinion Quarterly, Vol. 30, No. 2, p. 306, 1966.

27. U. S. Bureau of the Budget, Household Survey Manual 1969, p. 58, 1969 .

28. Nie, Norman, Bent, Dale, and Hul1, C. Hadlai, Statistical Package for the Social Sciences, McGrawHill, 1970 .

29. Lazerwitz, Bernard, "Sampling Theory and Procedures", Methodology in Social Research, by Blalock, Hubert, Jr. and Ann B., New York, McGraw-Hi11, p. 314, 1968. 


\section{APPENDICES}




\section{APPENDIX A}

Pilot-Test Questionnaire 
The pilot-test questionnaire had five questions for obtaining resident's opinions about the community. The four questions which covered general "likes" and "dislikes" at the community and neighborhood levels are shown below. Shown on the following page is the initial format design used for the category question.

1. What features of the Greater Lafayette Area do you like the most?

2. What features of the Greater Lafayette Area do you dislike the most?

4. First, what features of your neighborhood do you like the most?

5. What features of your neighborhood do you dislike the most? 
Alphabetically listed below are ten major categories of community concern.

1. Cultural Activities

2. Education

3. Health Care \& Sanitation

4. Housing

5. The Local Economy

6. Local Government

7. Pub1ic Assistance

8. Public Safety

9. Pub1ic Transportation $\&$ Utilities

10. Recreation

11. Other

3. Are there any facilities, services, or conditions you would like to see improved within these major categories?

Yes _ No Don'k Know _ If "YES", what improvements would you like to see made?

(Write your answer in the spaces below)

How Soon?

Right Very Soon

1. In Category No. , I would like to see Now Soon

2. In Category No. _, I would like to see

3. In Category No. __, I would like to see

4. In Category No. , I would like to see

5. In Category No. , I would like to see

6. In Category No. , I would like to see

7. In Category Nò. , I would like to see 
APPENDIX B

Pre-Test Questionnaire 
Nio.

\section{COMMUNTTY IMPROVEMENT SURVEY}

\section{DIRECTIONS:}

Most of the following questions allow you to write-in what you think in your own words. Please answer as many of these questions as possible. Agein, the results of this survey will not make any reference to answers from an individual household.

1) First, we would like to know how lons you have lived in the Greater Lafayette Area? years

2) What part of the Greater Iafayette Area do you live in? Lafayette West Lafayette

3) How long have you lived at your present address? years

4) What features of the Greater Lafayette Area do you Ilke the most? 
5) Listed below are (11) categories of communty concern. If improvements could be made in oniy (5) of these categories right now, in which (5) would you like to see improvement?

Please check $(\checkmark)$ below.

Community Appearance

Education

___ Environmental Protection

Health Care

_ Hous1ng

_ Iocal Economy
Local Government
Publ1c Assistance
Publ1c Safety
Recreation and Cultural Activities
Transportation and Public Ut1lities
Other

None _ No Opinion 
1. Comonity Appearance

2. Education

3. Enviromentel Protection

4. Health Care

5. Housing

6. The Local Econom
7. Local Government

8. Public Assistance

9. Public Safety

10. Recreation \& Cultural Activities

11. Transportation \& Public Utillties

12. Other

7) Are there aby facilities, services, or conditions you would like to see improved within the for categories above?

Yes No Don't Know

If "Yps", what imorovements would you like to see made? (Write your answer in the spaces below)

1. In Category No. I would like to see

2. In Category No. I would like to see

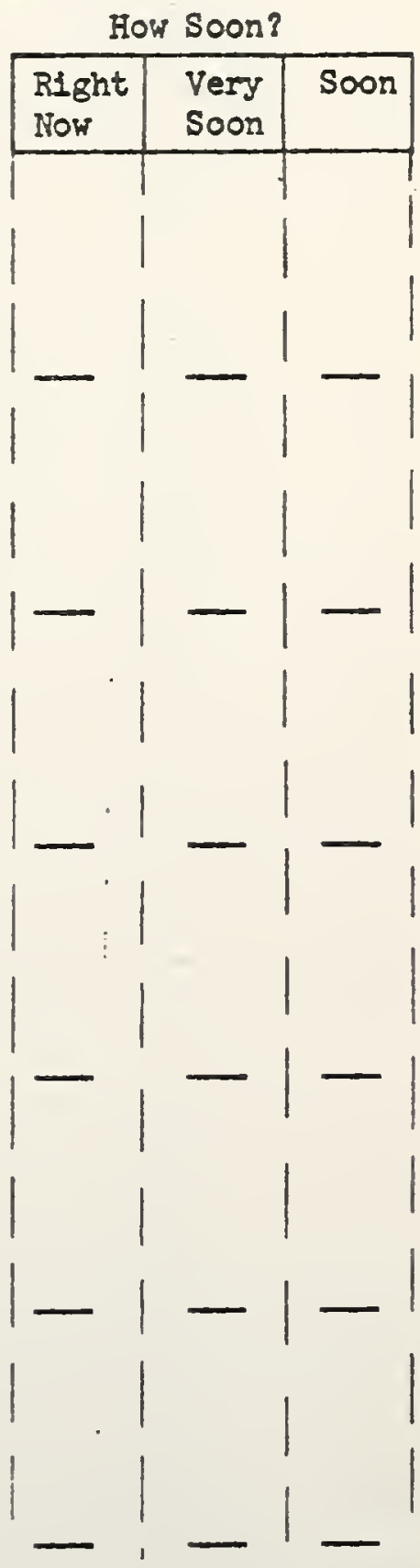

5. In Category No. , I would like to see

6. In Category No. I would like to see I would like to see 
Listed below are sorne specific items of local concern. How Important do you think each of these items would be for improving the Greater Lafayette Area? (Check one box for each item).

a. Unflyling the local governments

b. Developing the Lafayette riverfront as a golf course and park area

c. Speed-up widening of bypess

d. Eliminating downtown railroad crossings

e. Incressing downtown parking

f. Expending the operation of local day care centers

8. Establlshing a city-wlde rocational high school

h. Keeping and Improving the local bus system

1. Emergency center for drus abuse

j. Restoring the city court house

k. Downtown urben renewal

1. Increasing the supply of housing

m. Stricter enforcement of traffic laws

n. Inproving the location of shopping facilities

o. Air pollution control

p. Butlding Wildcat reservoir

q. Attracting more industry to the Lafayette aree

r. Other

B. 
Now, we would like to know what you think about your part of the Groater Iafayette Area.

(9) First, what features of your "part of town" do you like the most? No Opinion

10) What features of your "part of town" do you dislike the most? No Opinion

11) How long do you expect to Iive in the Greater Lafayette Area? Indefinftely

Only a few years

At most only a year

Don't reelly know

Other 
12 You are a man ___ Married

a woman

Single

13 You have completed: (Circle only one)
Grade School High School
College or Trade School
$\begin{array}{lllllllll}0 & 1 & 2 & 3 & 4 & 5 & 6 & 7 & 8\end{array}$
1234
1253456 (years)

(24)

You are presently:

1. employed full or part time

2. housewlfe

3. ret1red

4. unemployed

5. college student

6. other

15) THANK YOU for your help. If you have any further suggestions please write them below. 
APPENDIX C

Final Questionnaire Design 


\section{GRFATER IAFAYETTE \\ COMMUHITY THFROVEMENT STUDY}

DIRECTIOHS: Host of the following questions can be quickiy checked or filled-in. Others allow you to answer in your own words.

(1) First, il would like to know how long you have lived:

$$
\begin{aligned}
& \text { a. in the Lafayette area? __ yrs. } \\
& \text { b. at your present address? __ yrs. }
\end{aligned}
$$

(2) How long do you expect to live in the Lafayetice area?
[] Indefinitely
[] At most, only a year
[? Onily a few years
[] Don't Really know

Al2 citiee seem to have their good and bad points.

(3) rirst, what features of the Greater Lafayctte area do you like the most?

[] No Opinion

Figure Cl. Final Questionnaire - Page 1 
(4) Listed below are some major categories in thich iocal inprovements might be made. Please check( $/)$ the three (3) categories in which you think the Lafayette area needs the most improyement.

[] 1. Coinmunity Appearance

[] 7. Local Government

[] 2. Education

[] 8. Puibic Assistance

[] 3. Environmental Protection

[] 9. Public Safety

[] 4. llealth Care

[]10. Public Utilities

[] 5. Housing

[]11. Recreation

[] 6. Local Economy

[]12. Transportation

[] No Opinion

5 Are there particular facilities, services, or conditions you would like to sec improved within any of the categories above?

[] Yes [] No [] Don't know a. If "Yes", what improvements would you like to see made? (Please write your answer(s) in the spaces below)

1. In Category No. _., I would like to see

2. In Category No. ..., I would like to see

3. In Category No. _, I would like to see

4. In Category No. _., I would like to see

b. If you suggested more than one improvement above, vinich one would you like to see done first?

suggestion No.

Figure C2. Final Questionnaire - Page 2 
(6) Listed below are some specific items of local concern.

How important do you think each of these items would be for improving the Lafayette area?

(Please cirole your answer for each item)

a. Public parking garages downtown

b. Combining City-County services: parks, police, fire, sewage, etc.

c. Expanding the County park system

d. Establishing an area-wide vocational high school

e. Expanding and improving the bus service

f. Increase the supply of public housing

g. Developing the Lafayette riverfront as a park area

h. Relocating the downtown railroads

i. Downtown urban renewal

j. Building wildcat reservoir

k. Other

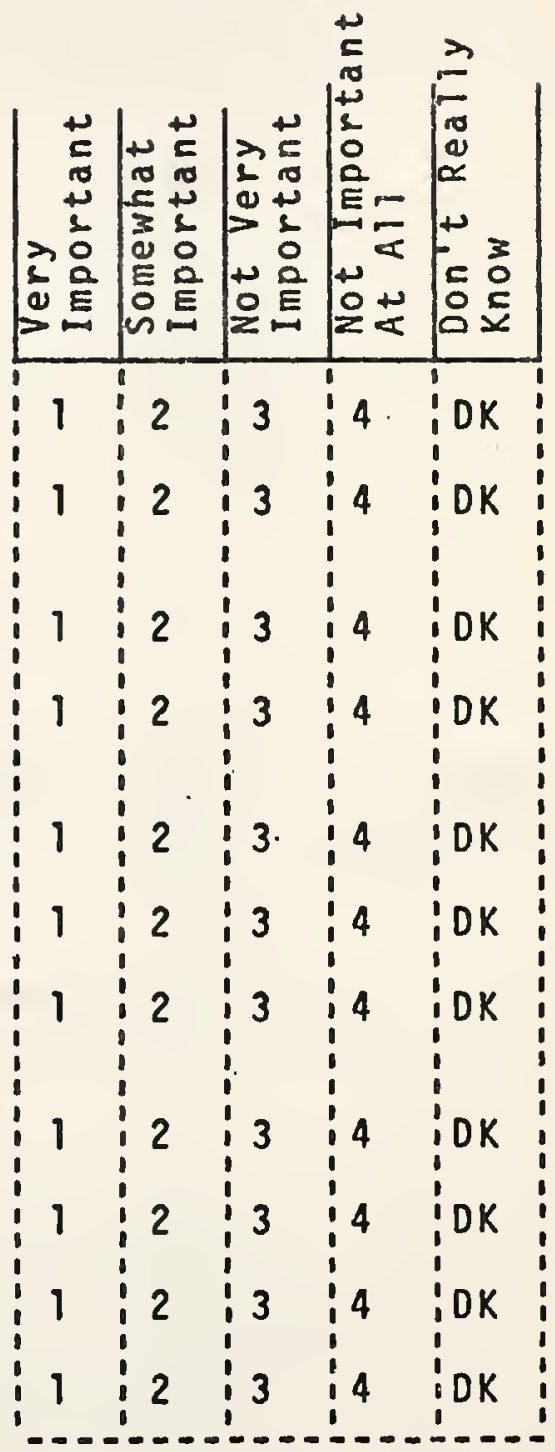

(7) Now, think for a moment about your part of town.

If the local city government could spend alot of money on a new program to improve your neighborhood, what do you think they should spend it on?

Figure. C3. Final Questionnaire - Page 3 
In a community-wide survey, a statistical check must be made to insure that all kinds of people have participated. We ask you to complete the following questions to make such a check possible.

- Your age bracket is:
[] Under 25 yrs. old
[] 35 to 44
[] 55 to 64
[] 25 to 34
[] 45 to 54
[] 65 or over

You are a: [] Male [] Female

- The years of education you have completed:

(Please circle one)

Grade School High School College, Business, or Trade $\begin{array}{llllllll:llllll}6 & \text { or less } & 7 & 8 & 9 & 10 & 11 & 12 & 13 & 14 & 15 & 16 & 17 & \text { or more }\end{array}$

- The number of persons living in your household is:

- Their relationship to you is:

(e.g.,. wife, husband, son, daughter, brother, uncle, etc.)

- The occupation of the head of your household is:

(e.g., clerk, machinist, typist, sales manager, fireman, etc.)

If you have any further suggestions for improving the Lafayette area, piease write them below. 
324 Ferry Street, Lafayette, Indiana

October, 1971

Dear Lafayette Area Resident:

Last year, the members of your household participated in the Greater Lafayette Transportation and Development Study. The questions you were asked in that study did not give you a chance to say what improvements you thought were needed in the Greater Lafayette area. The purpose of this present study is to find out what improvements you would like to see made in local community facilities, services, or conditions. The information will then be made available to the Greater Lafayette Transportation and Development Study still in progress.

It will take only a few minutes for one adult member of your household to answer the short enclosed questionnaire and return it in the stamped reply envelope. A2l answers you give wizl be confidential. The survey report will not make any reference to individual households.

The answers you give can help determine what needs to be improved in the Greater Lafayette area. Please return the completed questionnaire at your earliest convenience.

Thank you for your help.

Sincerely,

Gene Waltz

Study Coordinator

FIGURE C5. Cover Letter 


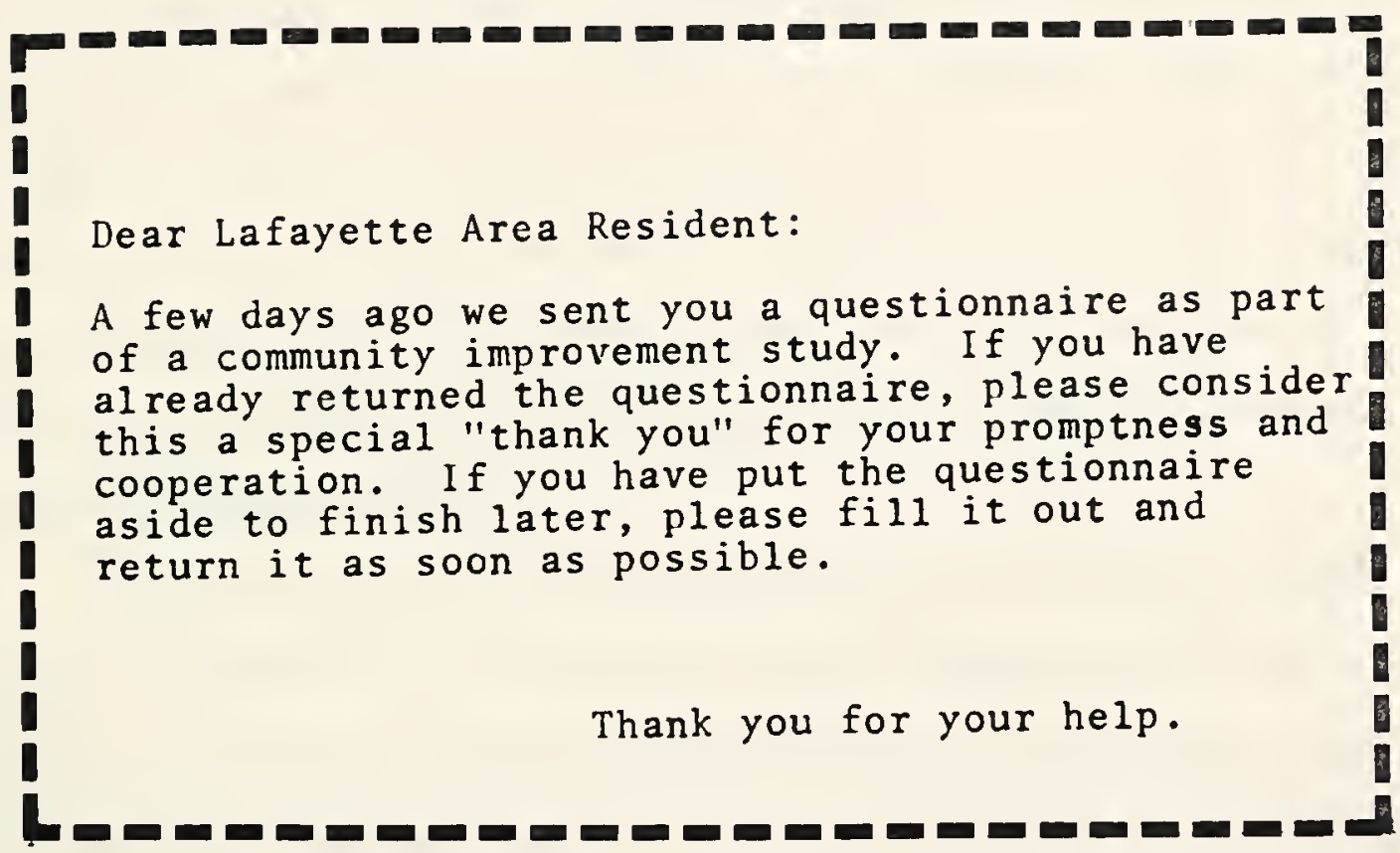

FIGURE C6. Post Card Reminder 
324 Ferry Street, Lafayette, Indiana

November, 1971

Dear Resident:

A few days ago your household should have received in the mail a questionnaire as part of a community improvement survey. We came to your household today to be sure that you did receive this questionnaire. Since you were not at home, we have left you a questionnaire to make sure you have a chance to indicate what improvements you think are needed in the Lafayette area.

It will take only a few minutes for one adult member of your household to answer the short questionnaire and return it in the stamped reply envelope. AZZ answers you give wilz be confidential.

Since the information obtained in this survey will be made available to the Greater Lafayette Transportation and Development study, we are making a special effort to encourage all selected households to respond. Please return the questionnaire at your earliest convenience.

Thank you for your cooperation

$$
\begin{aligned}
& \text { Sincerely, } \\
& \text { Gene Waltz } \\
& \text { Study Coordinator }
\end{aligned}
$$

FIGURE C7. Cover Letter For Personal Follow-Up 
APPENDIX D

Additional Survey Data 
The data obtained for the survey questions not reported in the text are summarily given below without discussion. An illustration of the coding procedure for question (5a) then follows:

\section{Question:}

1. First, we would like to know how long you have lived:

$$
\begin{aligned}
& \text { a. in the Lafayette area? } \bar{X}=23.3 \text { years } \\
& \text { b. at your present address? } \bar{X}=10.2 \text { years }
\end{aligned}
$$

2. How long do you expect to live in the Lafayette area?
$216[\mathrm{X}]$ Indefinitely
$15[\mathrm{X}]$ At most, only a year
$24[\mathrm{X}]$ Only a few years
$49[\mathrm{x}]$ Don't really know

All cities seem to have their good and bad points.

3. First, what features of the Greater Lafayette area do you like the most?

\section{Response}

Purdue University

Shopping Facilities

Size of City

School system

Parks \& recreational facilities

Cultural activities

Friendly people

Cleanliness \& appearance

General economic condition

City services

Proximity to larger cities other

Respondents

No opinion

\section{$\underline{\text { Percent }}$}

11.9

11.7

9.4

7.8

7.8

5.5

5.1

4.9

4.9

3.5

3.3

24.2

100.0 
7. Now, think for a moment about your part of town.

If the local city government could spend a lot of money on a new program to improve your neighborhood, what do you think they should spend it on?

Response

Street or road repairs

Sidewalk repairs and installations

Traffic signals and overhead signs

Parks and recreational facilities

Street lights

General clean up

More police protection

Improving housing conditions

Don't spend it - reduce taxes

$O K$ as is

Parking facilities

Schools

Bicycle lanes

Other

Respondents

No answer

\section{Percent} 23.8 10.2

9.9

9.2

5.8

4.8

4.4

4.0

3.7

3.3

2.5

2.5

2.5

13.4

100.0

For question (5 a), 77.3 percent (235) of the respondents gave one or more specific suggestions for improvement. Many of the responses to this question consisted of several different suggestions. These were isolated and counted as separate suggestions. The resulting number of specific suggestions was 730 which averaged out to 4.2 suggestions per respondent.

A complete list was then made of all the responses. With this list, each response was coded by major category. Most of the responses logically fell within a given category. Some responses, however, could be placed under two different categories due to their interrelatedness. For example, 
some overlap existed between the public safety and transportation categories. Suggested changes in the transportation system for the sake of public safety could logically fall under either, e.g., bicycle lanes. The classification of these "troublesome" type of responses into two categories by the respondents also reflected the interrelated aspects of some of the facilities, services, and conditions with the major categories. When responses such as those above could not be classified within a given category on any technical basis, the categorical classification of the reponse used by the majority of the respondents was used for the analytical classification. The categorical assignment of responses could vary slightly with the analyst doing the classifying, but would not be such that it would change the overall results.

Minor categories were then developed to code the specific suggestions under each major category. The minor categories for each major category are shown in Table D1 to illustrate the classification scheme which was used. Some examples of the verbatim responses obtained are listed on the pages following Table D1.

A direct count was made of the number of responses which the respondents classified in a category different from that assigned by the analytical scheme. In those cases where a respondent did not indicate a category classification for his response, the response was counted 
as a misclassification with respect to the analytical scheme. The percent agreement with respondents was 87.6 for some 730 responses. This high degree of agreement indicates that the categorical labels were commonly meaningful to most of the respondents. The overlap between the public safety and transportation and between the local economy and local government categories created the major portion of the classification differences. 
TABLE D1. Minor Categories of Suggested Improvements In Each Major Category

Responses

Community Appearance

91

1. Restoration of downtown buildings 29

2. Better cleaning of streets and alleys 13

3. Better upkeep of homes and yards (by owners)

4. More weeds cut and general clean-up in vacant lots

5. The Wabash River bank cleaned-up 5

6. Unsightly, delapidated buildings removed 4

7. Junk cars hauled away 4

8. Restoration of historical places 3

9. Other 18

Education $\quad 41$

1. More vocational training opportunities 10

2. School construction costs reduced 6

3. Better teaching 6

4. Wider range of subjects in curriculums 5

5. More government aid to private schools 3

6. Hot lunch program for grade school 2

7. More discipline 2

8. Other 7

Environmental Protection $\quad 61$

1. Strict control of air pollution 23

2. The Wabash River cleaned up 15

3. More recycling of waste 7

4. Sewage treatment facilities improved to
reduce water pollution

5. Less noise pollution 2

6. Other 7 
TABLE D1. Continued

Responses

Health Care

1. Medical assistance for low-income groups 5

2. More hospitals and clinics 4

3. More and less expensive nursing homes 3

4. Mobile centers offering free pap smear tests 2

5. Lower hospital and doctor costs 2

6. More doctors 2

7. Other 5

Housing

1. More lower cost housing for retired and low income groups

2. Lower rent or housing costs 12

3. Housing codes improved and enforced 10

4. Better quality housing 4

5. Slum areas cleaned up 3

6. Other

Local Economy

1. More jobs

2. More diversified industry

3. Other

Local Governments

1. Lower taxes and tax money used better 21

2. A change in City-County office holders 11

3. A combination of Lafayette-W. Lafayette city governments

4. A government more responsive to the interests of the people

5. Stricter law enforcement by courts

6. A commission similar to a better business bureau

7. Other 
TABLE D1. Continued

Responses

\section{Public Assistance}

1. More liberal application of funds

2. Improvement of services

3. Less welfare recipients

4. More help for the elderly

5. Other

Public Safety

1. Better enforcement of traffic laws, speed limits, etc.

2. More traffic signals and overhead signs

3. A larger police force to improve protection

4. Sidewalks improved for pedestrian safety 8

5. More street 1 ighting

6. A reduction in speed limits in residential areas

7. Other

Public Utilities

1. The telephone service improved

2. The water works and sewage treatment department checked out

3. Regulation of Cable TV

4. Buried telephone 1 ines

5. Other 
TABLE D1. Continued

Responses

Recreation

71

1. More neighborhood parks for children

13

2. Columbian Park improved (e.g., zoo cleaned up, eliminate commercial rides)

3. The riverfront park developed

4. More recreational facilities for young and old adults

5. Wildcat reservoir built

6. More night entertainment places

7. Other

Transportation

1. The bus system improved routes, scheduling, fares, etc.

2. The polluting buses eliminated

3. The downtown railroad tracks relocated

4. Improvements to aid traffic flow (overhead signs, signals, street widening, etc.)

5. Bike lanes

6. More parking facilities

7. Other 


\section{Question (5a):}

I would like to see:

"more done in renovating buildings downtown; please preserve some of the older buildings; e.g. courthouse has been a good start"

"a mall downtown"

"clean up riverfront; a new park along the riverfront not for golfers but for kids and the community"

"less money being spent on schools that are being built so elaborate; need the schools but could be put up cheaper without lots of the luxuries they have"

"less 'country club' high schools"

"a trade school (or schools) for the young people not college bound"

"the govt. take over the re-cycling; it can be profitable, or at least the cost of landfill is avoided"

"encouragement of waste disposal on an individual basis thru tax credits"

"mobile centers offering free pap smear examinations as well as chest $x$-rays"

"more doctors so a person doesn't have to wait so long for an appointment"

"substandard housing eliminated by forcing landlords to improve \& maintain properties" 
1 would like to see:

"W. Laf. develop \& enforce a housing code similar to Laf. which at least is fair to the tenant"

"a housing code developed where there is more uniform planning rather than patchwork here \& there"

"a major effort to locate industry here making us less dependent on Purdue \& several large employers"

"a zoning commission more responsive to the people \& less responsive to the needs of the greedy"

"more prosecution of felonies in the courts instead of all these people getting off"

"a better business bureau or some consumer protection agency developed"

"less welfare recipients - make those able to work get off their duff $\&$ work instead of fostering 3 rd generation welfare families"

"more liberal application of welfare funds"

"that the phone company is no longer the biggest joke in Laf."

"the utilities more responsive and able to explain their rates - especially the waterworks \& sewage treatment dept."

"the water company be "honest" on their billing out their water bills; I think the govt. should check into this matter; something fishy down there" 
I would like to see:

"widening Union St. from 21 st east; then, painting a yellow "no passing" stripe all the way from the Harrison bridge to the by-pass; if you think this would not help traffic, you should go home that way from Purdue every night"

"better bus service"

"mini-buses on the road instead of empty 40 passenger smokers"

"buses that do not choke you with exhaust fumes"

"new buses; old = pollution"

"mo re attention to bike routes along or parallel to major streets"

"get those trains out of town"

"no parking on narrow streets"

"what is now being planned" 

